\title{
Dynamic interplay between photodamage and photoprotection in photosystem II
}

\author{
Alexandra J. Townsend* | Maxwell A. Ware* | Alexander V. Ruban
}

School of Biological and Chemical Sciences, Queen Mary University of London, London E14NS, UK

\section{Correspondence}

A. V. Ruban, School of Biological and Chemical Sciences, Queen Mary University of London, Mile End Rd, Fogg Building, London E14NS, UK.

Email: a.ruban@qmul.ac.uk

\section{Funding information}

BBSRC, Grant/Award Number: BB/L019027/

1; Royal Society Wolfson Research Merit Award

\begin{abstract}
Photoinhibition is the light-induced reduction in photosynthetic efficiency and is usually associated with damage to the D1 photosystem II (PSII) reaction centre protein. This damage must either be repaired, through the PSII repair cycle, or prevented in the first place by nonphotochemical quenching (NPQ). Both NPQ and D1 repair contribute to light tolerance because they ensure the long-term maintenance of the highest quantum yield of PSII. However, the relative contribution of each of these processes is yet to be elucidated. The application of a pulse amplitude modulation fluorescence methodology, called protective NPQ, enabled us to evaluate of the protective effectiveness of the processes. Within this study, the contribution of NPQ and D1 repair to the photoprotective capacity of Arabidopsis thaliana was elucidated by using inhibitors and mutants known to affect each process. We conclude that NPQ contributes a greater amount to the maintenance of a high PSIl yield than D1 repair under short periods of illumination. This research further supports the role of protective components of NPQ during light fluctuations and the value of protective NPQ and $\mathrm{q}_{\mathrm{Pd}}$ as unambiguous fluorescence parameters, as opposed to $q_{1}$ and $F_{v} / F_{m}$, for quantifying photoinactivation of reaction centre II and light tolerance of photosynthetic organisms.
\end{abstract}

\section{KEYWORDS}

Arabidopsis thaliana, chlorophyll fluorescence, NPQ, photoinactivation, PSII repair cycle

\section{1 | INTRODUCTION}

The sedentary lifestyle of plants combined with the fluctuating light environment they normally grow in necessitates mechanisms that can mitigate or repair damage to the photosynthetic machinery. Photosystem II (PSII) is a large pigment-protein complex necessary for the light-dependent oxidation of water to molecular oxygen in cyanobacteria and chloroplasts. PSII is predominantly located in the stacked grana regions of chloroplasts, where it is organized in supercomplexes containing dimeric cores associated with light harvesting antenna (Boekema, van Roon, \& Dekker, 1998; Danielsson et al., 2006; Theis \& Schroda, 2016). The D1/D2 heterodimer lies within the reaction centre $(\mathrm{RC})$ of the core complex and is the site of primary photochemistry (Nanba \& Satoh, 1987). D1 is vital for photosynthesis as it constitutes the binding site to the oxygen evolving complex and $\mathrm{Mn}_{4} \mathrm{Ca}$ cluster; however, it is highly susceptible to photodamage (Telfer, Bishop, Phillips, \& Barber, 1994; Vass, Styring, Hundal, Koivuniemi, \& Aro, 1992). Although the

"Alexandra J. Townsend and Maxwell A. Ware contributed equally to this work. accessory pigments and components that form the antenna are highly efficient at absorbing light, the subsequent energy transfer and redox reactions in the $\mathrm{RC}$ are comparatively slower. This disparity can create a bottleneck leading to a build-up of excitation energy and the formation of reactive oxygen species (Aro, Virgin, \& Andersson, 1993; Barber, 1995; Ohad, Kyle, \& Arntzen, 1984). This excess energy and resultant damage must be dealt with, either through dissipative processes to prevent energy accumulation or through the repair of damage to the photosynthetic machinery. Photoinhibition is the lightinduced reduction in the photosynthetic capacity of an organism and is often reflected by the permanent damage and closure of RCII (Powles, 1984). Here, we use the term photoinactivation to describe the light-induced inactivation and therefore functional closure of RCs, including damage, which leads to a decrease in the yield of PSII ( $\Phi_{\text {PSII }}$; Murata, Allakhverdiev, \& Nishiyama, 2012). The susceptibility of a plant to photoinactivation depends upon multiple factors including life history (e.g., growing conditions), genetic adaption, and physiological status (Aro et al., 1993; Demmig-Adams, Cohu, Muller, \& Adams, 2012). A number of strategies exist in order to prevent or minimize photoinactivation (Ruban, 2009), including the efficient 
repair of damage during the PSII repair cycle or dissipative pathways that prevent energy accumulation and harmlessly remove it (Aro et al., 1993).

As the primary site of photoinhibitory damage, the D1 protein has a high rate of turnover (Mattoo, Hoffman-Falk, Marder, \& Edelman, 1984). This is accomplished through the efficient PSII repair cycle, which involves the partial disassembly of the PSII core complex, degradation, and de novo synthesis of the light-damaged D1 protein followed by reassembly (Aro et al., 1993; Järvi, Suorsa, \& Aro, 2015; Nixon, Barker, Boehm, de Vries, \& Komenda, 2005; Nixon, Michoux, Yu, Boehm, \& Komenda, 2010; Tyystjärvi, 2013). A critical step in D1 turnover is the degradation of the damaged polypeptide (Bailey et al., 2002). D1 degradation involves cleavage at a site in the stromal loop (Bailey et al., 2002; Canovas \& Barber, 1993; Greenberg, Gaba, Mattoo, \& Edelman, 1987) and involves the $\mathrm{FtsH}$ protease that belongs to the AAA protein superfamily (ATPases associated with a variety of cellular activities; Latterich \& Patel, 1998; Lindahl et al., 2000; Nixon et al., 2005). The PSII repair cycle typically occurs over hours (Koivuniemi, Aro, \& Andersson, 1995; Nixon et al., 2010) with the minimum half time for D1 protein turnover at $30 \mathrm{~min}$ (Aro et al., 1993). Although the repair cycle is constantly enforced with damage occurring at all light intensities, if the rate of damage to D1 exceeds the repair capacity, then $\Phi_{\mathrm{PSII}}$ will be undermined (Aro et al., 1993).

Alternative strategies exist to simply divert energy away from RCs and therefore limit photoinactivation of RCll, which leads to the D1 damage. The fastest process employed by plants to relieve excitation pressure on the photosynthetic membrane is nonphotochemical quenching (NPQ) of chlorophyll fluorescence, where excess energy is dissipated harmlessly as heat via chlorophyll-chlorophyll and/or chlorophyll-carotenoid interactions (Horton \& Ruban, 1992; Jahns \& Holzwarth, 2012; Ruban, 2012, 2016; Wahadoszamen, Berera, Ara, Romero, \& van Grondelle, 2012). NPQ consists of a number of components: qE, qT, qZ, and ql (Adams, Demmig-Adams, \& Winter, 1990; Adams, Zarter, Mueh, Amiard, \& Demmig-Adams, 2006; Ruban, Johnson, \& Duffy, 2012). The fastest and photoprotective component is $\mathrm{q}_{\mathrm{E}}$, or energy-dependent quenching, and is triggered by the generation of a $\mathrm{pH}$ gradient across the thylakoid membrane $(\Delta \mathrm{pH}$; Krause, 1974; Horton, Wentworth, \& Ruban, 2005). $q_{E}$ is also known to be modulated by the carotenoid zeaxanthin and the protein PSII subunit $S$ (PsbS), which act as allosteric regulators to alter the structure of the membrane and antenna conformation in order to enhance the affinity for protons, thus facilitating $\mathrm{q}_{\mathrm{E}}$ formation and relaxation (Demmig, Winter, Kruger, \& Czygan, 1987; Funk et al., 1995; Goral et al., 2012; Horton et al., 2005; Johnson et al., 2011; Li et al., 2000; Li, Phippard, Pasari, \& Niyogi, 2002; Noctor, Rees, Young, \& Horton, 1991; Rees et al., 1992; Rees, Young, Noctor, Britton, \& Horton, 1989; Ruban, 2012, 2016; Ruban \& Horton, 1999; Sacharz, Giovagnetti, Ungerer, Mastroianni, \& Ruban, 2017). qz is reliant upon the formation of zeaxanthin (Nilkens et al., 2010; Ruban, Young, \& Horton, 1993), and q is associated with closure to RCs as well as slow photoprotective components of NPQ (Demmig-Adams \& Adams, 2006; Jahns \& Holzwarth, 2012; Krause, 1988; Matsubara \& Chow, 2004; Ruban et al., 2012). The components of NPQ are often distinguished based on their speed of formation and relaxation; however, there is considerable overlap in these kinetics, and many features are present in more than one component (such as zeaxanthin formation and structural reorganization; Jahns \& Holzwarth, 2012). This may lead to ambiguous or misleading results when investigating their effective protective nature based on these features alone (Ruban \& Murchie, 2012; Ruban \& Belgio, 2014; Giovagnetti \& Ruban, 2015).

Despite extensive research on photoprotective processes, there is no current consensus on the contribution of each to the light tolerance of PSII (Aro et al., 1993; Jahns \& Holzwarth, 2012; Ruban et al., 2012; Tyystjärvi, 2013). Simultaneous assessment of all processes contributing to the photoprotection of RCII has been difficult due to the need for disruptive light treatments or invasive techniques (i.e., D1 protein quantification) in the estimation of photodamage (Aro et al., 1993; Greenberg et al., 1987; Tyystjärvi \& Aro, 1996). Pulse amplitude modulation (PAM) fluorometry has been key to photosynthesis research as any process effecting the $\Phi_{\text {PSII }}$ can be observed as a change in the yield of chlorophyll fluorescence (for full reviews, see Genty, Briantais, \& Baker, 1989; Maxwell \& Johnson, 2000; Brooks \& Niyogi, 2011; Murchie \& Lawson, 2013). However, until recently, it has been difficult to assess damage during light exposure due to the traditional parameters used to measure it. For example, $F_{v} / F_{m}\left(\left[F_{m}-F_{o}\right] / F_{m}\right)$ has been the principally used as a parameter in fluorescence, which gives information on the maximum quantum yield of PSII photochemistry (Butler, 1978; Genty et al., 1992). For this reason, a sustained decrease in $F_{v} / F_{m}$ has often been equated to photodamage only, and the effects of altered structure/function of photosynthetic apparatus or the induction of sustained protective quenching was largely overlooked (Adams et al., 2006; Adams \& Demmig-Adams, 2004; Long, Humphries, \& Falkowski, 1994; Maxwell \& Johnson, 2000; Murchie \& Lawson, 2013). Furthermore, as NPQ effects $F_{m}\left(N P Q=\left[F_{m} / F_{m}{ }^{\prime}\right]-1\right)$ and RC closure manifests as a rise in $F_{\mathrm{o}}$ (Demmig \& Björkman, 1987; Oxborough \& Baker, 1997), it is difficult to determine these separate effects on $F_{\mathrm{v}} / F_{\mathrm{m}}$, which encompasses both $F_{\mathrm{o}}$ and $F_{\mathrm{m}}\left[F_{\mathrm{v}} /\right.$ $\left.F_{\mathrm{m}}=\left(F_{\mathrm{m}}-F_{\mathrm{o}}\right) / F_{\mathrm{m}}\right]$. Further, $F_{\mathrm{v}} / F_{\mathrm{m}}$ requires long dark adaptation periods, the length of which can vary, leading to uncertainty over results (Ruban \& Murchie, 2012; Ware, Dall'Osto, \& Ruban, 2016). Another traditionally used parameter is $\mathrm{q}_{\mathrm{l}}$, but the rate of q, recovery due to damage is often comparable with the rate of recovery of protective NPQ (pNPQ) components such as $\mathrm{q}_{z}$ (Adams et al., 2006; Adams \& Demmig-Adams, 2004). Therefore, as both photoinactivation/ photodamage and NPQ undermine the $\Phi_{\mathrm{PSII}}$, it is often not possible to distinguish between each scenario using just the $F_{\mathrm{v}} / F_{\mathrm{m}}$ parameter (Ruban \& Murchie, 2012).

The existence of multiple NPQ and repair pathway components acting over different time periods necessitated the development of an approach to test the in vivo photoprotective function. Ruban and Murchie (2012) developed a new protocol for the measurement of NPQ that can provide information of the protective effectiveness of processes occurring in the photosynthetic membrane in a relatively rapid, non-destructive way. The protocol entails a gradually increasing actinic light (AL) routine to track the relationship between $\Phi_{\mathrm{PSII}}, \mathrm{NPQ}$, and $q_{p}$ (the quantum coefficient of photochemical quenching) measured in the dark following light exposure (termed $\mathrm{q}_{\mathrm{Pd}}$; see Section 2 for the theory and Figure 1 for a representative fluorescence trace). This parameter can be used to define $\mathrm{pNPQ}$-the NPQ and corresponding preceding $\mathrm{AL}$ intensity treatment after which all $\mathrm{RC}$ s remain 


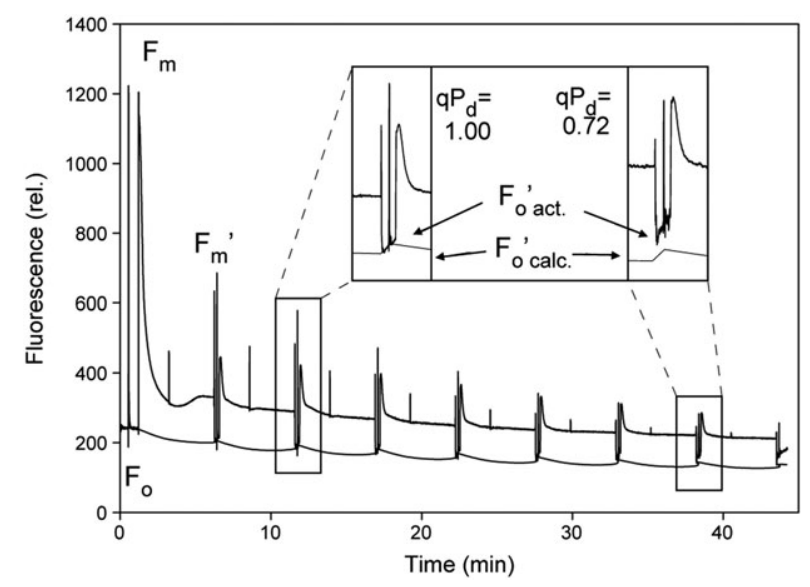

FIGURE 1 Scheme of induction of chlorophyll fluorescence from a wild-type Col-0 plant with an eight-step actinic light (AL) routine. For a detailed explanation of the routine development, see Ruban and Belgio (2014). Inset: the gradually increasing AL routine induces photoinactivation and photodamage, which can be readily observed as a divergence between $F_{\mathrm{o}}{ }^{\prime}$ act and $F_{\mathrm{o}}{ }^{\prime}$ calc and be seen as a decrease in the $\mathrm{q}_{\mathrm{Pd}}$ parameter

active (i.e., open). This method provides a number of advantages over previous methods and allows a quantitative approach to define the relationship between photoinactivation and NPQ and their contribution to the decline in the $\Phi_{\mathrm{PSI}}$. When RCs close, they cause an increase of fluorescence in the dark, and $F_{\mathrm{o}}{ }^{\prime}$ will rise. This was clearly noticed by Demmig and Björkman (1987) and led to the development of the Oxborough and Baker (1997) formula, which predicts discrepancy between the actual $F_{\mathrm{o}}{ }^{\prime}\left(F_{\mathrm{o}}{ }^{\prime}\right.$ act. $)$ and the calculated $F_{\mathrm{o}}{ }^{\prime}\left(F_{\mathrm{o}}{ }^{\prime}\right.$ calc. $)$. Therefore, $\mathrm{q}_{\mathrm{Pd}}$ provides a prompt marker of both initial and long-term photoinactivation as it reflects the true state of RCs enabling the tracking of the early signs of their loss of activity. Previously, the $\mathrm{qP}_{\mathrm{d}}$ parameter has been found in a linear correlation with the rate of oxygen evolution following the onset of the photoinactivation of PSII (Giovagnetti \& Ruban, 2015). It differs from the previously mentioned $\mathrm{q}_{\mathrm{l}}$ and $F_{\mathrm{v}} / F_{\mathrm{m}}$ parameters as they rely on $F_{\mathrm{m}}$, which is affected mainly by NPQ. Also, and most importantly, the D1 degradation kinetics do not follow the RCIl photoinactivation kinetics that is actually tracked by the $\mathrm{q}_{\mathrm{Pd}}$ parameter. Previous work has shown that short timescales ( $30 \mathrm{~min})$ of constant high light $\left(2,000 \mu \mathrm{mol} \mathrm{m} \mathrm{m}^{-2} \mathrm{~s}^{-1}\right)$ are not sufficient to lead to a significant reduction in D1 protein content, despite a large reduction in $\mathrm{q}_{\mathrm{Pd}}$ (Giovagnetti \& Ruban, 2015) due to the insufficient time available for removal of the damaged polypeptide (Aro et al., 1993; Tyystjärvi, 2013). Thus, the contribution of the PSII repair cycle during short periods of illumination is unknown.

Previously, the pNPQ protocol has been used to study the contribution of photosystem I (PSI) fluorescence to NPQ (Giovagnetti \& Ruban, 2015); the role of carotenoids and components of NPQ in light tolerance (Ruban \& Belgio, 2014; Tian, Ungerer, Zhang, \& Ruban, 2017; Ware et al., 2016; Ware, Belgio, \& Ruban, 2014); the variation in photoprotective capacity during ontogenesis (Carvalho, Ware, \& Ruban, 2015); and the coupling of PSII antenna to RCII plus the protective capacity of NPQ in plants acclimated plants acclimated to different growth conditions (Ware, Belgio, \& Ruban, 2015). Here, we have applied these methods with the aim to (a) quantify the relative contribution of D1 repair and NPQ to the high light tolerance of Arabidopsis thaliana during short-term illumination ( 40 min); (b) define the factors determining the balance between these two processes; and (c) assess the applicability of different fluorescence parameters, namely, $F_{\mathrm{v}} / F_{\mathrm{m}}, \mathrm{q}_{\mathrm{l}}, \mathrm{q}_{\mathrm{Pd}}$, and $\mathrm{pNPQ}$, for the study of photoprotection.

\section{2 | MATERIALS AND METHODS}

\section{1 | Plant material and growth conditions}

Wild-type (WT) Col-0, PsbS overexpressor (L17), and yellow variegated (var2-2) A. thaliana seeds were sterilized in $50 \%$ ethanol and $0.1 \%$ Triton-X 100 and stored for $72 \mathrm{hr}$ at $4{ }^{\circ} \mathrm{C}$ prior to sowing. Plants were grown on a 6:6:1 ratio of John Innes No. 3 soil, Levington M3 potting compost and perlite (Scotts UK, Ipswich, UK). All seedlings were grown under $100 \mu \mathrm{mol} \mathrm{m} \mathrm{m}^{-2} \mathrm{~s}^{-1}$ for 1 week before being transferred to $190 \mu \mathrm{mol} \mathrm{m} \mathrm{m}^{-2} \mathrm{~s}^{-1}$, with a 10 -hr photoperiod at $22^{\circ} \mathrm{C}$. Plants were watered into the trays 3 times a week. Fluorescence and biochemical measurements were made on plants that were between 40 and 60 days old that showed no sign of inflorescence.

\section{2 | Theory}

The $\Phi_{\mathrm{PSII}}$ is undermined by two processes: NPQ of chlorophyll $a$ fluorescence and the photodamage of RCII.

$$
\phi_{P S I I}=\frac{q_{P d} \cdot \frac{F_{\mathrm{v}}}{F_{\mathrm{m}}}}{\left[1+\left(1-\frac{F_{\mathrm{v}}}{F_{\mathrm{m}}}\right) \cdot N P Q\right]} .
$$

$F_{\mathrm{v}} / F_{\mathrm{m}}$ is the maximum photochemical quantum yield of PSII, which is calculated as $\left(F_{m}-F_{o}\right) / F_{m}$, with $F_{m}$ and $F_{o}$ being the maximum and minimum yields of fluorescence, respectively. NPQ is calculated as $\left(F_{m}-F_{m}{ }^{\prime}\right)-1$. $q_{P d}$, the coefficient of photochemistry in the dark, is calculated as

$$
q_{P d}=\frac{\left(F_{m}{ }^{\prime}-F_{o}{ }^{\prime} \text { act }\right)}{\left(F_{m^{\prime}}-F_{o}{ }^{\prime} \text { calc }\right)},
$$

where $F_{\mathrm{o}}{ }^{\prime}$ act and $F_{\mathrm{o}}{ }^{\prime}$ calc are the actual and calculated minimum levels of fluorescence in the dark after prior $\mathrm{AL}$ illumination. $F_{\mathrm{o}}{ }^{\prime}$ calc is quantified according to the formula of Oxborough and Baker (1997):

$$
F_{o}^{\prime}{ }_{\text {calc }}=\frac{1}{\frac{1}{F_{o}}-\frac{1}{F_{m}}+\frac{1}{F_{m}{ }^{\prime}}} .
$$

Figure 1 shows a representative fluorescence trace for the pNPQ procedure performed on a WT Col-0 leaf (see Section 2 for full details). Eight increasing $A L$ intensities were used in each measurement, thus representing the dynamics of a sunrise irradiance. Under low light intensities, the $F_{\mathrm{o}}{ }^{\prime}$ calc matches $F_{\mathrm{o}}{ }^{\prime}$ act, , however under high light intensities, to two $F_{\mathrm{o}}{ }^{\prime}$ values diverge (Figure $1 \mathrm{~b}$ ). This is due to the rise in minimum fluorescence caused by the photoinduced permanent closure of RCII. This causes $F_{\mathrm{o}}{ }^{\prime}$ calc $<F_{\mathrm{o}}{ }^{\prime}$ act and $\mathrm{q}_{\mathrm{Pd}}<1.00$, and at this point, the leaf is considered to be photodamaged. Due to natural variation, we 
use a $\mathrm{q}_{\mathrm{Pd}}$ of 0.98 as a mark of photodamage (i.e., $>2 \%$ of RClls are damaged). When $\mathrm{q}_{\mathrm{Pd}}>0.98, \mathrm{NPQ}$ is considered to be protective and is thus called pNPQ. For a detailed description of the principles of the method, see Ruban and Murchie (2012). Such values can be used to calculate population light tolerance curves, the percentage of the population that are photoinhibited at each light intensity, as $100 \times \mathrm{N}_{\mathrm{qPd}}<0.98 /$ $\mathrm{N}_{\text {total. }}$ A regression analysis can be performed using SigmaPlot 13.0 (Sigmoidal fit, Hill 3 parameter, $f=a^{*} x^{\wedge} b /\left[c^{\wedge} b+x^{\wedge} b\right]$ ), from which the phototolerance of the population can be readily calculated.

\section{3 | Flourescence Measurements}

\subsection{1 | Protective NPQ procedure}

\section{Chloroplasts}

Intact chloroplasts were prepared by homogenizing dark adapted fresh leaf tissue in semifrozen grinding medium $(0.45 \mathrm{M}$ sorbitol, $20 \mathrm{mM}$ Tricine, $10 \mathrm{mM}$ ethylenediaminetetraacetic acid, $10 \mathrm{mM} \mathrm{NaHCO}$, $0.1 \%$ bovine serum albumin, $\mathrm{pH}$ 8.4) with a Polytron. The homogenate was then filtered through four layers of muslin followed by two layers of muslin and one layer of cotton wool. The filtrate was centrifuged for $2 \mathrm{~min}$ at $3,500 \mathrm{~g}\left(4^{\circ} \mathrm{C}\right)$. The chloroplast-enriched pellet was resuspended in resuspension medium (0.3 M sorbitol, $20 \mathrm{mM}$ Tricine, $5 \mathrm{mM} \mathrm{MgCl}_{2} 2.5 \mathrm{mM}$ ethylenediaminetetraacetic acid, $\mathrm{pH}$ 7.6). The resulting pellet was then resuspended with a small volume of resuspension medium and put on ice. Chlorophyll concentration was determined as using the method of Porra, Thompson, and Kriedemann (1989). Chloroplast intactness was verified using the $F_{\mathrm{v}} / F_{\mathrm{m}}$ values that averaged 0.751 for all chloroplast experiments.

Protective NPQ assessment was performed on intact chloroplasts (35 $\mu \mathrm{g} \mathrm{ml}^{-1}$ chlorophyll final concentration; Johnson \& Ruban, 2011; Ware et al., 2016) using a DUAL-PAM-100 fluorimeter (Walz, Effeltrich, Germany). The procedure was carried out as in leaves (see below). The pNPQ assessment procedure (Figure 1a) entails eight increasing AL intensities of 95, 170, 286, 448, 698, 865, 1,076, and $1,667 \mu \mathrm{mol} \mathrm{m} \mathrm{m}^{-2} \mathrm{~s}^{-1}$. Each AL increment lasts for $5 \mathrm{~min}$, before a saturating pulse (SP) is applied in the light to measure the NPQ. The AL is then turned off for $10 \mathrm{~s}$ but with far red (FR) light on, before another $\mathrm{SP}$ is applied to measure the photochemical quenching in the dark $\left(q_{P d}\right)$. After this SP, the AL is turned on for another 5 min at the next $\mathrm{AL}$ intensity. The procedure was run as a preprogramed batch file with the scheme: (SP)-(AL on)-(120 s)-(SP)-(180 s)-(SP)-(AL off/FR on)-(7 s)(SP)-(5 s)-(AL on/FR off)-repeat. For treatment, $1 \mathrm{mM}$ lincomycin, $50 \mathrm{mM} \mathrm{NH}_{4} \mathrm{Cl}, 200 \mu \mathrm{M}$ diaminodurene (DAD), or a combination was added to the chloroplast suspension prior to the $\mathrm{pNPQ}$ procedure.

\section{Leaves}

Protective NPQ measurements on whole intact leaves were performed using a JUNIOR-PAM fluorimeter (Walz, Effeltrich, Germany) and magnetic leaf clip unless indicated otherwise. Plants were dark adapted for $45 \mathrm{~min}$ before each procedure. The $\mathrm{pNPQ}$ assessment procedure (Figure 1a) used AL intensities of 126, 266, 399, 588, 875, 1,148, 1,610 , and $2,100 \mu \mathrm{mol} \mathrm{m} \mathrm{m}^{-2} \mathrm{~s}^{-1}$. Intensities of $83.3 \%$ and $66.7 \%$ of these were also used for greater representation of leaf variation by adjusting the AL settings in the Walz software. For leaf infiltration experiments presented in Figure 3, leaves were removed leaving a long petiole. The leaf was tightly wrapped in cotton wool, which was soaked in buffer (0.3 M sorbitol, $20 \mathrm{mM}$ HEPES, $\mathrm{pH}$ 7.5) and where stated lincomycin $(1 \mathrm{mM})$ or nigericin $(100 \mu \mathrm{M})$ and aluminium foil for $45 \mathrm{~min}$. After this time, leaves were removed from cotton and the pNPQ assessment procedure applied using $\mathrm{AL}$ intensities as above. A constant high light procedure was also developed following the same scheme as the increasing $\mathrm{AL}$ routine, but all eight steps were set to $2,100 \mu \mathrm{mol} \mathrm{m} \mathrm{m}^{-2} \mathrm{~s}^{-1}$. For the constant light routine, vacuum infiltration was used (as opposed to soaked cotton wool) due to the risk of wilting under high light conditions and sorbitol was omitted from buffers. In order to evaluate whether the chloroplasts preparation or leaf infiltration effects the function of the system, the $F_{v} / F_{m}$ values for WT Col-0 chloroplasts, control infiltrated leaves, and intact leaves were compared. There was no significant difference between the $F_{v} / F_{m}$ between the three experimental methods (nonpooled variance two-sample $t$ test; Figure S1).

\subsection{2 | Chlorophyll fluorescence induction}

Chlorophyll fluorescence induction was measured with a Dual PAM 100 chlorophyll fluorescence photosynthesis analyser (Walz, Effeltrich, Germany) using 30 min of light illumination followed by 15 min of dark relaxation. Plants were adapted in the dark for 40 min before measurements were obtained. Actinic illumination of $216 \mu \mathrm{mol} \mathrm{m} \mathrm{m}^{-2} \mathrm{~s}^{-1}$ was provided by arrays of $635-\mathrm{nm}$ light-emitting diodes illuminating both the adaxial and abaxial surfaces of the leaf. $F_{\mathrm{o}}$ (the fluorescence level with open RClls) was measured in the presence of $9 \mu \mathrm{mol} \mathrm{m}^{-2} \mathrm{~s}^{-1}$ measuring beam. Maximum fluorescence in the dark adapted state $\left(F_{\mathrm{m}}\right)$ during the course of actinic illumination $\left(F_{m}{ }^{\prime}\right)$ and in the subsequent dark relaxation periods was determined using a 0.8-s saturating light pulse $\left(4,000 \mu \mathrm{mol} \mathrm{m} \mathrm{m}^{-2} \mathrm{~s}^{-1}\right)$. An SP was applied $10 \mathrm{~s}$ after the end of the light exposure to measure $\mathrm{q}_{\mathrm{Pd}}$ and after the 15-min dark period to measure $\mathrm{q}_{\mathrm{I}}$ and $F_{\mathrm{v}} / F_{\mathrm{m}}$. We defined the quantum yield of PSII $\left(F_{\mathrm{v}} /\right.$ $\left.F_{\mathrm{m}}\right)$ as $\left(\left(F_{\mathrm{m}}-F_{\mathrm{o}}\right) / F_{\mathrm{m}}\right), \mathrm{NPQ}$ as $\left(\left(F_{\mathrm{m}}-F_{\mathrm{m}}{ }^{\prime}\right) / F_{\mathrm{m}}{ }^{\prime}\right), \mathrm{q}_{\mathrm{Pd}}$ as $\left(\left(F_{\mathrm{m}}{ }^{\prime}-F_{\mathrm{s}}\right) / F_{\mathrm{o}}\right)$ following $10 \mathrm{~s}$ of dark, and $\mathrm{q}_{1}$ as the NPQ following 15-min dark relaxation, where $F_{\mathrm{s}}$ is the steady-state fluorescence level.

\subsection{3 | Three-hour light treatment and Western blots}

In order to see how the decline in $\mathrm{q}_{\mathrm{Pd}}$ can equate to the amount of photodamage, a longer term light treatment was carried out. Leaves were exposed to $2,200 \mu \mathrm{mol} \mathrm{m} \mathrm{s}^{-2} \mathrm{~s}^{-1}$ for $3 \mathrm{hr}$ and the $\mathrm{q}_{\mathrm{Pd}}$ monitored every $10 \mathrm{~min}$ following $10 \mathrm{~s}$ of FR illumination. After $3 \mathrm{hr}$, the leaves were immediately frozen in liquid nitrogen for Western blot analysis. Unstacked thylakoids were isolated from $10 \mathrm{~g}$ of leaf mass as previously described (Ruban et al., 2006) with the modification that $\mathrm{MgCl}_{2}$ was omitted from all the buffers. Sodium dodecyl sulphate-polyacrylamide gel electrophoresis was carried out essentially according to Laemmli (1970) including $6 \mathrm{M}$ urea in both the stacking and resolving gels. Solubilized thylakoids ( $1 \mu \mathrm{g}$ of $\mathrm{Chl}$ ) were separated on a $12 \%$ $(\mathrm{w} / \mathrm{v})$ acrylamide gel and blotted onto a nitrocellulose membrane (GE Healthcare, UK). The proteins were incubated overnight at $4{ }^{\circ} \mathrm{C}$ with antibodies raised against D1 (see Bailey et al., 2002). Protein 
quantification was carried out using ImageJ (National Institutes of Health, Bethesda, MD). The $\mathrm{q}_{\mathrm{Pd}}$ and relative band density following 3-hr illumination is given in Figure S2.

\section{3 | RESULTS}

\section{1 | Quantifying light tolerance of chloroplasts treated with effectors of D1 repair or NPQ}

Intact chloroplasts provide a useful system for studying the effects of NPQ and PSII repair on light tolerance as they exclude the possibility for chloroplast movement within leaves to influence tolerance (Kasahara et al., 2002). Furthermore, they allow the infiltration of effectors such as lincomycin, uncouplers, and DAD. Lincomycin is an antibiotic and a specific inhibitor of chloroplast translation (Järvi et al., 2015; Tyystjärvi \& Aro, 1996). Here, it was used to block D1 synthesis and thus prevent repair of damaged PSII following light exposure; therefore, any tolerance present can be attributed solely to $\mathrm{NPQ}$. $\mathrm{NH}_{4} \mathrm{Cl}$ acts as an uncoupler and can be used to eliminate the proton gradient of thylakoid membranes, critical for the formation of NPQ (Krogmann, Jagendorf, \& Avron, 1959; Walters \& Horton, 1991). Thus, any tolerance present in the presence of the uncoupler can be attributed to D1 repair. For chloroplast experiments, $\mathrm{NH}_{4} \mathrm{Cl}$ was used as it is readily dissolved in aqueous solution thus is more suitable than ethanol-based uncouplers in intact chloroplast suspensions. In comparison, DAD can be used to stimulate artificial cyclic electron flow around PSI, and thus increase the $\mathrm{pH}$ gradient and enhance NPQ (Johnson \& Ruban, 2011; Rees, Noctor, \& Horton, 1990).

Application of a gradually increasing $\mathrm{AL}$ routine results in a rise in NPQ and the gradual onset of the photoinactivation and photodamage to RCII (Figure 1; Ware et al., 2014; Ware, Belgio, et al., 2015; Ware et al., 2016; Ruban \& Belgio, 2014; Ware, Giovagnetti, Belgio, \& Ruban, 2015). The latter can be quantified as a divergence in $F_{o}{ }^{\prime}$ act and $F_{\mathrm{O}}{ }^{\prime}$ calc and the corresponding decline in $\mathrm{q}_{\mathrm{Pd}}$ (Figure 1, inset). Such $\mathrm{q}_{\mathrm{Pd}}$ values can be used to calculate population light tolerance curves, the percentage of the population that are photoinhibited at each light intensity (see Section 2). An example light tolerance curve for WT Col-0 chloroplasts is given in Figure 2a. Such curves can be used to characterize key features of the population, such as the maximum light intensity that showed no signs of photoinactivation in the whole population, the light intensity at which $50 \%$ of the population show the first signs of photoinactivation $\left(\mathrm{I}_{50 \%}\right.$; red line, Figure $\left.2 \mathrm{a}\right)$, and the minimum light intensity required to induce signs of photoinactivation in the whole population (Ruban \& Belgio, 2014). WT Col-0 chloroplasts show their first signs of photoinactivation at $200 \mu \mathrm{mol} \mathrm{m}^{-2} \mathrm{~s}^{-1} \mathrm{AL}$ (Figure 2a). This means that all leaves had $\mathrm{q}_{\mathrm{Pd}}$ values $>0.98$ up until $200 \mu \mathrm{mol} \mathrm{m} \mathrm{m}^{-2} \mathrm{~s}^{-1} \mathrm{AL}$. This value is reduced in the $\mathrm{NH}_{4} \mathrm{Cl}$-treated chloroplasts and higher in all other treatments, with DAD-treated chloroplasts showing no signs of photoinactivation until $\sim 850 \mu \mathrm{mol} \mathrm{m} \mathrm{m}^{-2} \mathrm{~s}^{-1} \mathrm{AL}$ (data not shown). Figure $2 \mathrm{~b}$ shows the light intensity causing $50 \%$ tolerance for each treatment. DAD-treated chloroplasts were significantly more tolerant than other treatments, with $50 \%$ of the population able to tolerate $\sim 990 \mu \mathrm{mol} \mathrm{m} \mathrm{m}^{-2} \mathrm{~s}^{-1}$ ( $t$ test, $p<.05$ ). This is a result of the enhanced NPQ under DAD conditions. DAD- and lincomycin-treated chloroplasts (a)

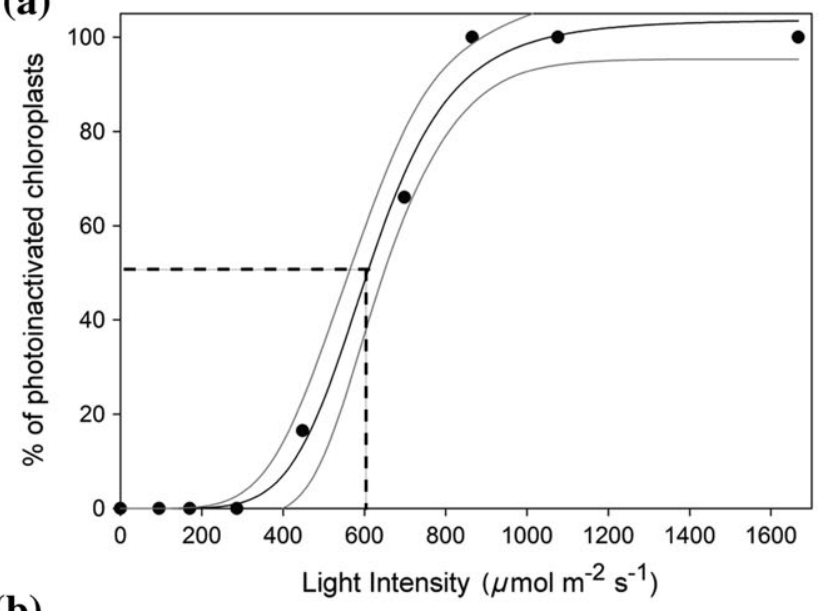

(b)

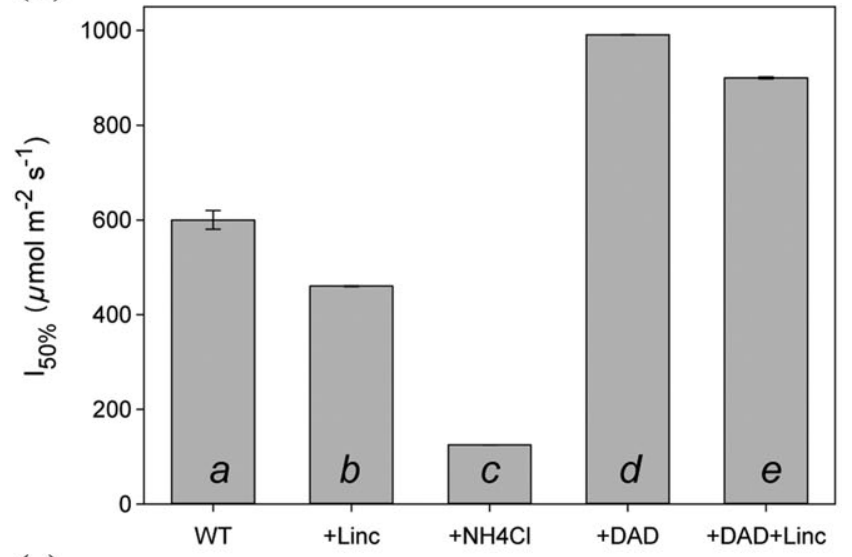

(c)

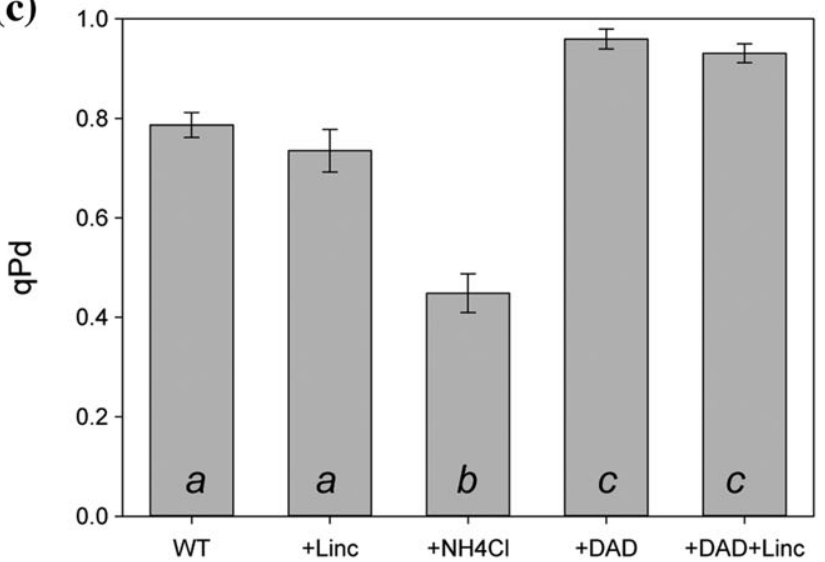

FIGURE 2 (a) Wild-type (WT) Col-0 chloroplast population tolerance curve calculated using the fluorescence routine presented in Figure 1 a on the Dual-PAM 100 (Walz) using actinic light intensities 95, 170, $286,448,698,865,1,076$, and $1,667 \mu \mathrm{mol} \mathrm{m}^{-2} \mathrm{~s}^{-1}$. Six repeats were performed at each light intensity. Chloroplasts were considered photoinactivated when $\mathrm{q}_{\mathrm{Pd}}<0.98$. Regression analysis and $95 \%$ confidence intervals were calculated using SigmaPlot 13.0 (Sigmoidal fit, Hill 3 parameter, $\left.f=a^{*} x^{\wedge} b /\left[c^{\wedge} b+x^{\wedge} b\right]\right)$. (b) The light intensity that caused photoinactivation in $50 \%$ of chloroplast samples $\left(I_{50 \%}\right)$. Error bars represent the scanning electron microscopy (SEM; $n=6$ ). Different letters correspond to significantly different results ( $t$ test, $p<.05)$. (c) The average $\mathrm{q}_{\mathrm{Pd}}$ value at the end of the fluorescence routine (Figure 1a). Error bars represent the SEM $(n=6)$. Different letters correspond to significantly different results ( $t$ test, $p<.05$ ). $\mathrm{DAD}=$ diaminodurene 
show the second highest tolerance at $900 \mu \mathrm{mol} \mathrm{m}^{-2} \mathrm{~s}^{-1}$, which is significantly greater than WT chloroplasts at $600 \mu \mathrm{mol} \mathrm{m}^{-2} \mathrm{~s}^{-1}$ and WT plus lincomycin-treated chloroplasts at $460 \mu \mathrm{mol} \mathrm{m} \mathrm{m}^{-2} \mathrm{~s}^{-1}$ ( $t$ test, $p<.05$ ). Therefore, the enhanced NPQ stimulated by DAD can sufficiently compensate for reduced tolerance invoked by blocking the PSII repair cycle. The $\mathrm{NH}_{4} \mathrm{Cl}$-treated chloroplasts showed the significantly lowest level of tolerance at $125 \mu \mathrm{mol} \mathrm{m}{ }^{-2} \mathrm{~s}^{-1}$ ( $t$ test, $\left.p<.05\right)$.

The extent of photoinactivation at the end of the increasing $\mathrm{AL}$ routine can be inferred from the value of $\mathrm{q}_{\mathrm{Pd}}$, as $\mathrm{q}_{\mathrm{Pd}}$ is a quantum coefficient that represents the total amount of RCll exposed to the AL, and is expressed as a value between 0 and 1.00 (Figure 2c). It is on this basis that $\mathrm{q}_{\mathrm{Pd}}$ represents the degree of photoinactivation leading to the RCll damage. Despite the decrease in light tolerance, the lincomycin treatment did not lead to a significant difference in $\mathrm{q}_{\mathrm{Pd}}$ relative to WT chloroplasts (i.e., WT vs. lincomycin) or under enhanced NPQ conditions (i.e., DAD vs. DAD + lincomycin; $t$ test, $p<.05$ ). However, enhanced NPQ (e.g., DAD treatment) significantly reduced the amount of photoinactivation relative to WT as seen by an increased $\mathrm{q}_{\mathrm{Pd}}$ value. $\mathrm{q}_{\mathrm{Pd}}$ was enhanced by $\sim 21.9 \%$ and $18.3 \%$ in response to DAD and $\mathrm{DAD}+$ lincomycin treatment, respectively (Figure 2c). This lead to a higher phototolerance under enhanced NPQ conditions (Figure 2b). Similarly, impaired NPQ (e.g., $\mathrm{NH}_{4} \mathrm{Cl}$ treatment) significantly increased photoinactivation relative to WT (Figure 2 c; $t$ test, $p<.05$ ) with a $43 \%$ decrease in $\mathrm{q}_{\mathrm{Pd}}$ relative to WT. Contrary to this, $\mathrm{q}_{\mathrm{Pd}}$ was only decreased by $\sim 6.6 \%$ in WT lincomycin-treated chloroplasts, relative to the WT control, suggesting that NPQ contributes a greater amount to phototolerance than D1 repair during short periods of illumination in chloroplasts.

\subsection{Quantifying light tolerance in leaves infiltrated with effectors to block D1 synthesis or NPQ}

Although intact chloroplasts provide a useful system for the infiltration of effectors and the study of photoprotective processes, the full activity of chloroplasts could be impaired during isolation or storage. Therefore, to further investigate the effect of impaired NPQ and D1 repair on light tolerance, infiltration of detached leaves was carried out. For the impaired NPQ treatment, the uncoupler nigericin was used as it is more effective for leaf infiltration than the hydrophilic $\mathrm{NH}_{4} \mathrm{Cl}$ (Johnson \& Ruban, 2014; Takahashi, Milward, Fan, Chow, \& Badger, 2009; Ware et al., 2014; Ware, Giovagnetti, et al., 2015). In order to test the contribution of D1 repair to light tolerance under enhanced NPQ conditions (as in DAD-treated chloroplasts), infiltration was also performed on L17 leaves, plants overexpressing the PsbS protein. Previous studies have shown that the approximate fivefold enhancement of PsbS in L17 can lead to up to twofold increase in NPQ capacity (Crouchman, Ruban, \& Horton, 2006; Li et al., 2002). The AL intensity causing 50\% photoinactivation and the $\mathrm{q}_{\mathrm{Pd}}$ value at the end of the procedure show a similar pattern to that seen for the chloroplasts (Figure 3a,b). The control infiltrated L17 leaves show the statistically greatest level of phototolerance, with $50 \%$ photoinactivation occurring at $1,007 \mu \mathrm{mol} \mathrm{m} \mathrm{m}^{-2} \mathrm{~s}^{-1}$ and the highest $\mathrm{q}_{\mathrm{Pd}}$ value at the end of the $\mathrm{AL}$ routine of 0.95 ( $t$ test, $p<.05$ ). This is followed by $L 17$ leaves infiltrated with lincomycin, with a $50 \%$ tolerance of $835 \mu \mathrm{mol} \mathrm{m} \mathrm{m}^{-2} \mathrm{~s}^{-1}$, which is significantly greater than WT leaves infiltrated with control buffer at
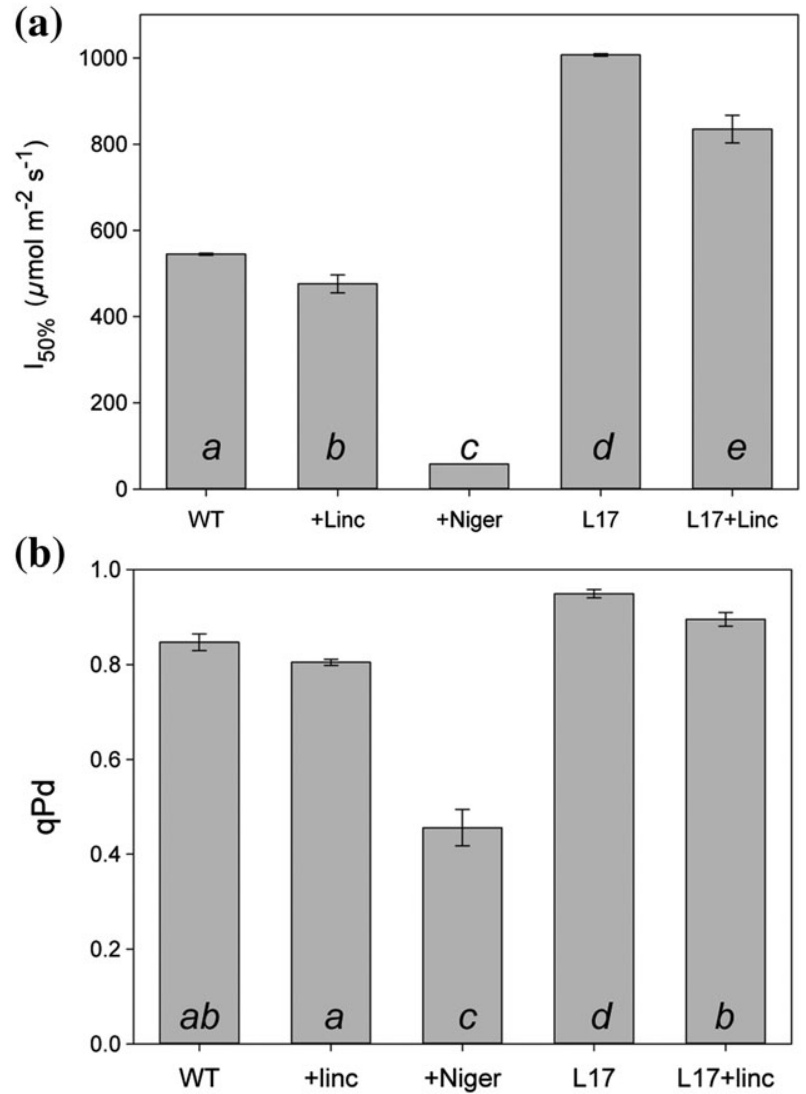

FIGURE 3 (a) The light intensity that caused photoinactivation in $50 \%$ of infiltrated leaves $\left(\mathrm{I}_{50 \%}\right)$. Wild-type (WT) Col-0 or L17 leaves were removed leaving a long petiole. The leaf was tightly wrapped in cotton wool, which was soaked in buffer (0.3 M sorbitol, $20 \mathrm{mM}$ HEPES) and where stated lincomycin ( $1 \mathrm{mM}$ ) or nigericin $(1 \mathrm{mM})$ and aluminium foil for $45 \mathrm{~min}$. After this time, leaves were removed from the cotton wool and the pNPQ assessment procedure (Figure 1a) applied using actinic light intensities of 126, 266, 399, 588, 875, 1,148, 1,610, and $2,100 \mu \mathrm{mol} \mathrm{m}{ }^{-2} \mathrm{~s}^{-1}$ on the Junior-PAM (Walz, Effeltrich, Germany). Error bars represent the scanning electron microscopy (SEM; $n=5)$. Different letters correspond to significantly different results ( $t$ test, $p<.05$ ). (b) The average $\mathrm{q}_{\mathrm{Pd}}$ value at the end of the fluorescence routine for infiltrated leaves. Error bars represent the SEM $(n=5)$. Different letters correspond to significantly different results ( $t$ test $p<.05)$

$545 \mu \mathrm{mol} \mathrm{m}{ }^{-2} \mathrm{~s}^{-1}$ ( $t$ test, $p<0.05$ ). Again, this indicates that enhanced NPQ can compensate for the reduction in tolerance cause by a blocked PSII repair cycle. The 50\% tolerance values for L17 and WT infiltrated leaves are approximately $100 \mu \mathrm{mol} \mathrm{m} \mathrm{m}^{-2}$ below those previously reported for noninfiltrated leaves (Ruban \& Belgio, 2014; Ware et al., 2014). This could be due to the altered transmission of light through an infiltrated leaf, which can increase the effective light intensity. Under control NPQ conditions (i.e., WT infiltrated leaves), $\mathrm{I}_{50 \%}$ was reduced by $13 \%$ and $90 \%$ following lincomycin and nigericin infiltration, respectively, relative to control infiltrated leaves, and $\mathrm{q}_{\mathrm{Pd}}$ at the end of the routine was reduced by $5 \%$ and $46 \%$, respectively. The disparity in the tolerance between lincomycin and nigericin infiltrated WT leaves suggests again that NPQ contributes a greater amount to phototolerance than D1 repair during the $\sim 40 \mathrm{~min}$ of illumination. 
In order to study the contribution of NPQ and D1 repair to photoprotection under different light conditions, measurements were repeated using the same procedure but with all eight illumination steps at 2,100 $\mu \mathrm{mol} \mathrm{m} \mathrm{m}^{-2} \mathrm{~s}^{-1}$ (see Section 2; Ruban \& Belgio, 2014; Ware et al., 2014). A constant, high light procedure enables analysis of photoprotective capacity under situations where NPQ is not able to form fully, and enables the kinetics of $\mathrm{q}_{\mathrm{Pd}}$ decline, and thus the onset of photoinactivation and eventual photodamage to be studied. Figure $4 \mathrm{a}$ shows the time course of the decrease in the $\mathrm{q}_{\mathrm{Pd}}$ decline for WT Col-0 vacuum infiltrated leaves. For both control and lincomycin-treated leaves, the major drop in $\mathrm{q}_{\mathrm{Pd}}$ occurred within the first 20 min of illumination, whereas nigericin infiltrated leaves show a more consistent and greater decrease in $\mathrm{q}_{\mathrm{Pd}}$ over the whole 42-min procedure. The decline in $\mathrm{q}_{\mathrm{Pd}}$, calculated from curve fitting, can be used as a means to extrapolate the time taken to induce photoinactivation (i. e., for $\mathrm{q}_{\mathrm{Pd}}$ to decline below 0.98: red line, Figure 4a). Figure 4b indicates that photoinactivation is induced in around $70 \mathrm{~s}$ in control leaves but within $20 \mathrm{~s}$ for nigericin infiltrated leaves, with lincomycin intermediate between the two. The amount of photoinactivation (assessed as the $\mathrm{q}_{\mathrm{Pd}}$ parameter at the end of the routine) is also significantly greater in nigericin infiltrated leaves, at only $46 \%$ of the WT value (Figure 4c). These results are consistent with a decreased NPQ formation in nigericin-treated leaves relative to control and lincomycin-treated leaves (data not shown). Taken together, the results presented in Figures 3 and 4 indicate the importance of NPQ and repair of inactivated/damaged D1 protein under both increasing and constant illumination.

\subsection{Quantifying light tolerance in intact leaves of plants with impaired D1 cleavage or enhanced NPQ}

To prevent unwanted effects on photosynthetic machinery caused by chemical stimulators or the infiltration process (e.g., Fiekers, Marshal, \& Parsons, 1979; Prior et al., 1990), we used attached leaves of the A. thaliana mutants var2-2 and L17. The var2-2 plants lack a homolog of $\mathrm{FtsH}-\mathrm{a}$ zinc metalloprotease required for the efficient repair of D1 at the stage of protein degradation (Bailey et al., 2002; Nixon et al., 2005). Therefore, these plants can be used to study impaired D1 repair (var2-2) and extra NPQ (L17) on photoprotection in a stable, in vivo system. In order to increase the $A L$ intensities used for measurement and collect a more representative spread of data in case of greater variation, the $\mathrm{AL}$ was adjusted in the advanced settings of the Junior-PAM to achieve $83.3 \%$ and $66.7 \%$ of the values (for a detailed description, see Ruban \& Belgio, 2014).

In accordance with the chloroplast and infiltrated leaf data, the enhanced NPQ condition, here the L17 plants, exhibited the significantly highest phototolerance with $50 \%$ photoinactivation occurring at $998 \mu \mathrm{mol} \mathrm{m} \mathrm{m}^{-2} \mathrm{~s}^{-1}$ ( $t$ test, $p<.05$; Figure $5 \mathrm{a}$ ). This is followed by WT Col-0 at $721 \mu \mathrm{mol} \mathrm{m} \mathrm{m}^{-2} \mathrm{~s}^{-1}$ and finally var2-2 at $592 \mu \mathrm{mol} \mathrm{m}$ ${ }^{-2} \mathrm{~s}^{-1}$. This same pattern was also reflected in the $\mathrm{q}_{\mathrm{Pd}}$ value at the end of the routine, which is significantly lower in var2-2 plants but not significantly different between L17 and WT ( $t$ test, $p<.05$; Figure $5 \mathrm{~b}$ ). This enhanced tolerance in the L17 plants can be attributed to the higher NPQ, which is almost $50 \%$ greater relative to WT Col-0 and var2-2 plants at 2,100 $\mu \mathrm{mol} \mathrm{m} \mathrm{m}^{-2} \mathrm{~s}^{-1}$ (Figure 5c).
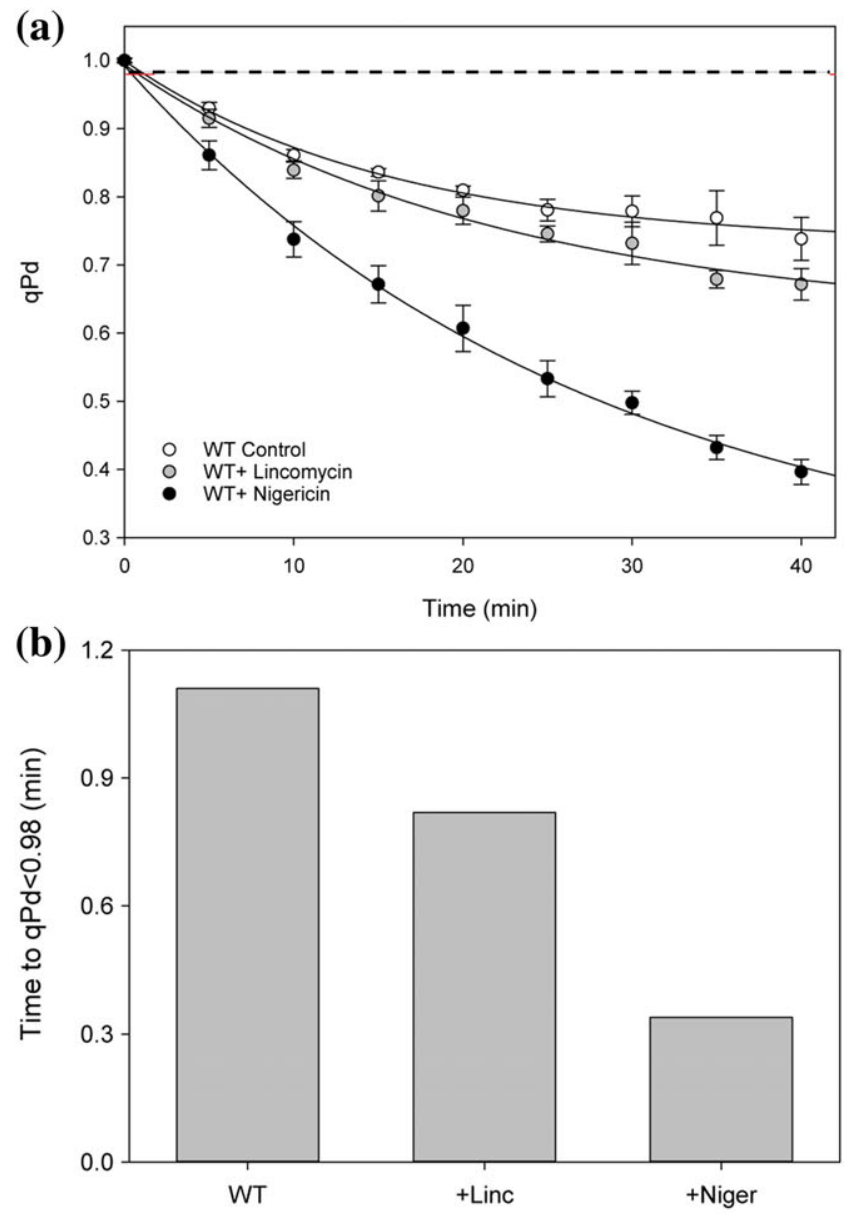

(c)

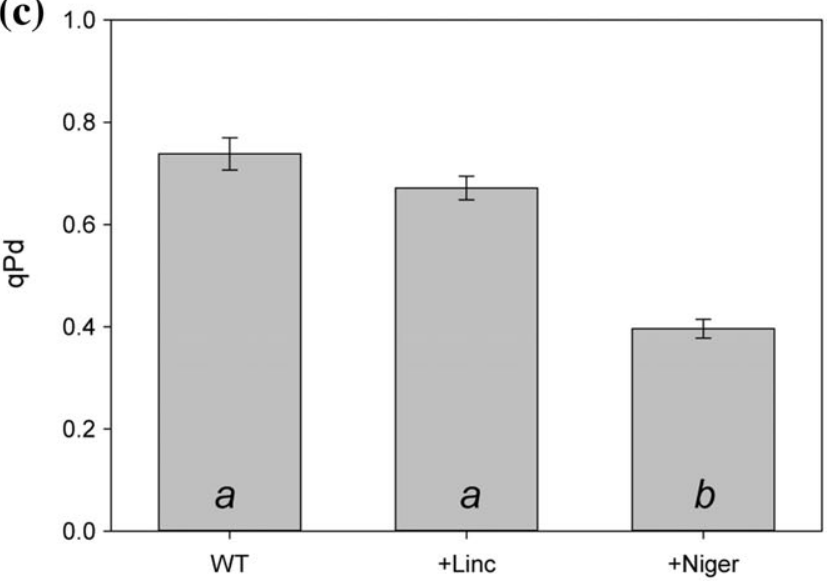

FIGURE 4 (a) The time course of $q_{P d}$ formation in vacuum infiltrated wild-type (WT) Col-0 Arabidopsis leaves induced by constant actinic light of 2,100 $\mu \mathrm{mol} \mathrm{m} \mathrm{m}^{-2} \mathrm{~s}^{-1}$ on the Junior-PAM (Walz, Effeltrich, Germany). Error bars represent the scanning electron microscopy (SEM; $n=3$ ). The time scheme of measurements was identical to those presented in Figure 1. Data fit was performed on SigmaPlot 13.0 (Exponential decay, single, three-parameter regression $[f=y 0+a x$ $\exp (-b x)]$ ). (b) The time taken for $\mathrm{q}_{\mathrm{Pd}}$ to decline below 0.98 (red line, Figure 4a) in infiltrated leaves. (c) The average $q_{P d}$ value at the end of the fluorescence routine for infiltrated leaves. Error bars represent the SEM $(n=3)$. Different letters correspond to significantly different results ( $t$ test, $p<.05$ )

Interestingly, there is no significant difference in the average NPQ value at 2,100 $\mu \mathrm{mol} \mathrm{m} \mathrm{m}^{-2} \mathrm{~s}^{-1}$ between WT Col-0 and var2-2 plants (Figure $5 \mathrm{c}$; $t$ test, $p<.05$ ). Taken together with the significant 

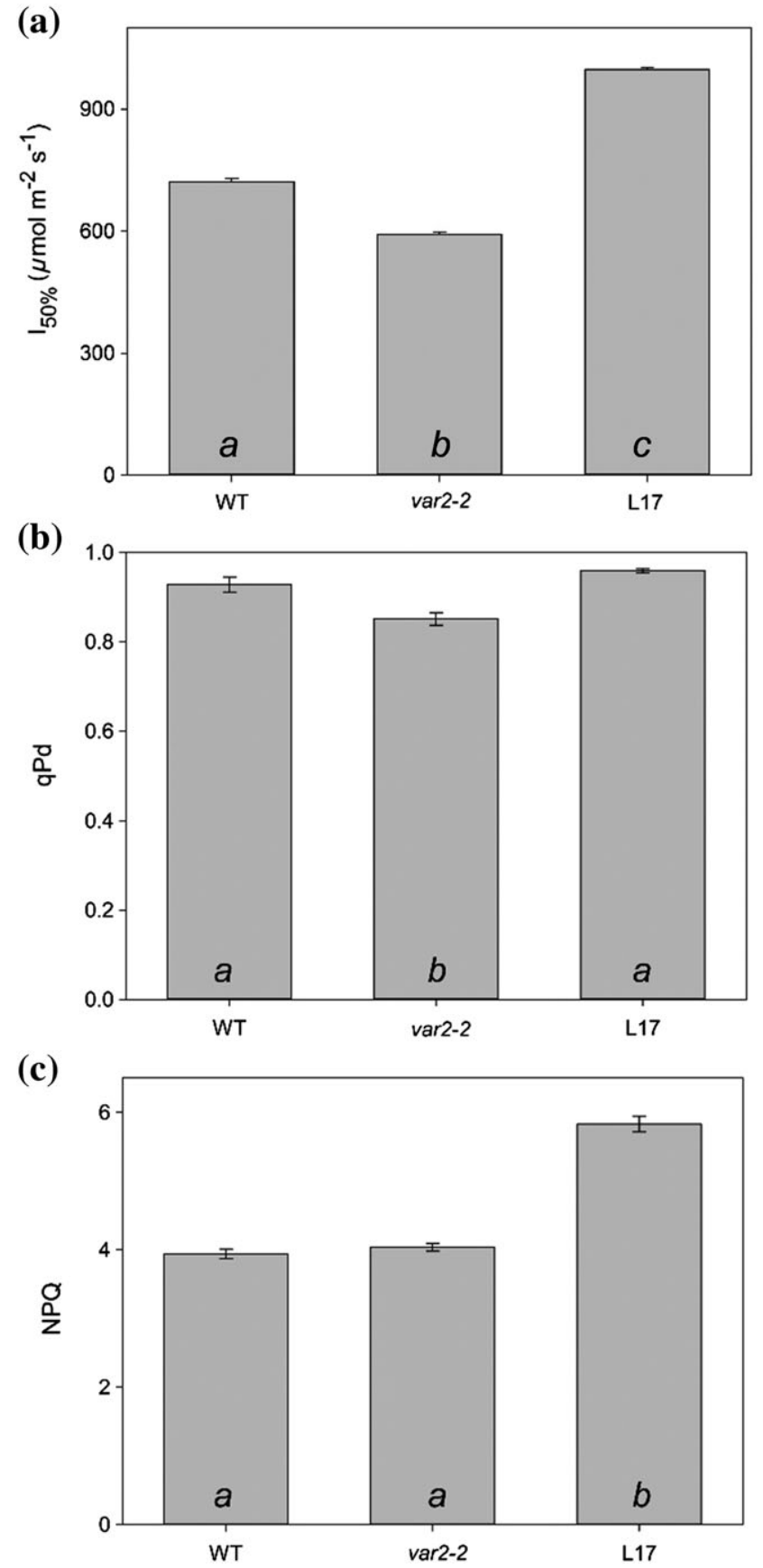

FIGURE 5 (a) The light intensity which caused photoinactivation in $50 \%$ of leaves for wild-type (WT) Col-0, var2-2, and L17 calculated using the fluorescence routine presented in Figure 1a on the JuniorPAM (Walz, Effeltrich, Germany) using actinic light intensities 126, $266,399,588,875,1,148,1,610$, and $2,100 \mu \mathrm{mol} \mathrm{m} \mathrm{m}^{-2} \mathrm{~s}^{-1}$. A total of $83.3 \%$ and $66.7 \%$ of these intensities were also used by altering the settings in the Walz program. Ten repeats were performed at each light intensity. Leaves were considered photoinactivated when $\mathrm{q}_{\mathrm{Pd}}<0.98$. Error bars represent the scanning electron microscopy (SEM; $n=10$ ). Different letters correspond to significantly different results ( $t$ test, $p<.05$ ). (b) The average $\mathrm{q}_{\mathrm{Pd}}$ value at the end of the fluorescence routine. Error bars represent the SEM $(n=5)$. Different letters correspond to significantly different results ( $t$ test, $p<.05$ )

difference in $50 \%$ tolerance (Figure $5 \mathrm{a}$ ) and the final $\mathrm{q}_{\mathrm{Pd}}$ value (Figure $5 b$ ), this suggests that although the capacity for NPQ has not been effected by the var2-2 mutation, the relationship between $\mathrm{pNPQ}$ and $\mathrm{q}_{\mathrm{Pd}}$ has altered.

\subsection{The effectiveness of new versus old fluorescence parameters in quantifying photodamage}

In order to compare old fluorescence parameters with the newer proposed $\mathrm{q}_{\mathrm{Pd}}$ parameter, a classic fluorescence induction experiment was carried out (Figure 6). During this experiment, intact leaves of WT Col0 and L17 were exposed to moderate light $\left(190 \mu \mathrm{mol} \mathrm{m} \mathrm{m}^{-2} \mathrm{~s}^{-1}\right)$ for $30 \mathrm{~min}$ followed by $15 \mathrm{~min}$ of dark relaxation (Figure 6a). This $\mathrm{AL}$ is similar to the conditions in which the plants were grown and thus should not induce photodamage. An SP was applied $10 \mathrm{~s}$ after the end of the light treatment in order to measure $\mathrm{q}_{\mathrm{Pd}}$, and another pulse was applied after 15-min dark relaxation. At this point, it is expected that the faster acting components of NPQ (namely, $q_{E}$ and $q_{T}$ ) will have relaxed and thus remaining NPQ can approximately be attributed to q (Adams et al., 1990; Adams et al., 2006; Demmig \& Winter, 1988; Horton \& Hague, 1988; Jahns \& Holzwarth, 2012; Ruban et al., 2012). Values of $q_{P d}, F_{v} / F_{m}$ and $q_{1}$ are given in Figure $6 b$. The $q_{P d}$ parameter indicates that RCs are still fully open in WT Col-0 and L17 plants $\left(q_{P d} \sim 1.00\right)$. This is expected based on $\mathrm{PNPQ}$ procedure and associated light tolerance curves, which indicate that the majority of

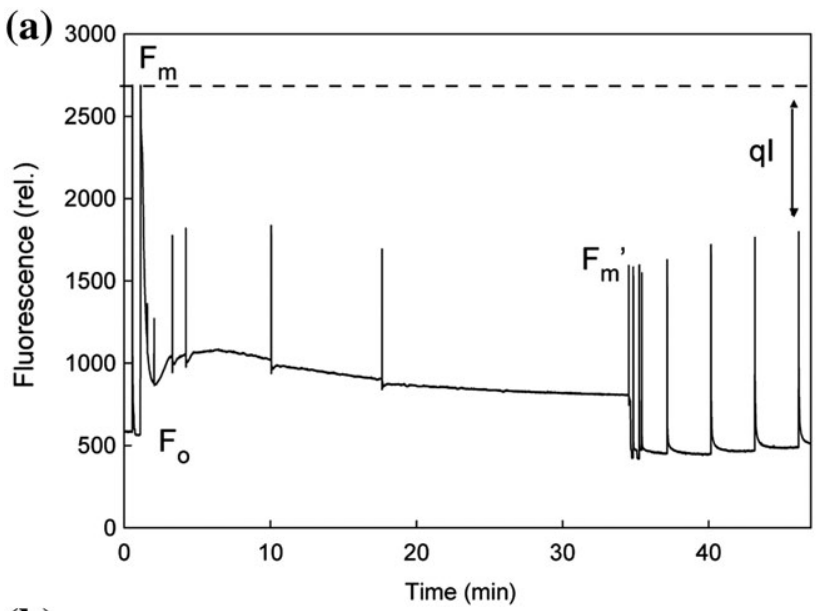

(b)

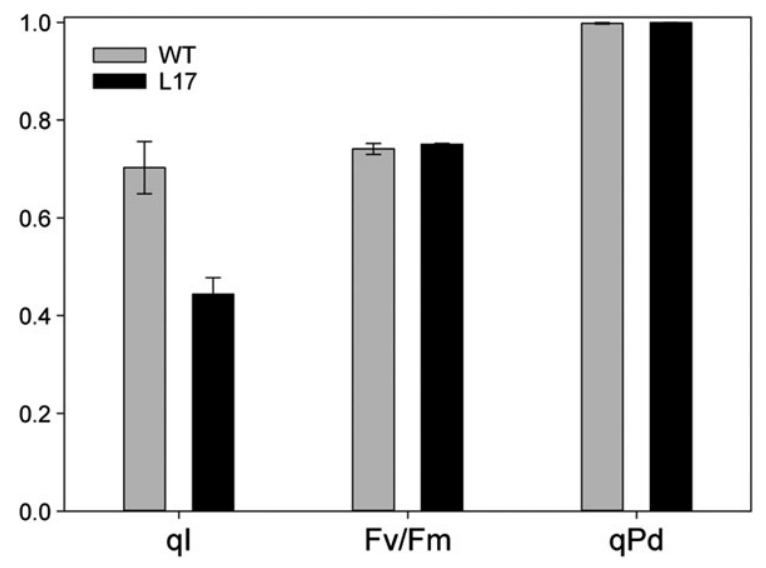

FIGURE 6 (a) Pulse amplitude modulation fluorescence induction trace for a wild-type (WT) Col-0 plant exposed to $260 \mu \mathrm{mol} \mathrm{m} \mathrm{m}^{-2} \mathrm{~s}^{-1}$ for $30 \mathrm{~min}$ prior to 15 -min dark relaxation. (b) $\mathrm{q}_{\mathrm{l}}$, $\mathrm{q}_{\mathrm{Pd}}$, and $F_{\mathrm{v}} / F_{\mathrm{m}}$ measured for WT Col-0 and L17 plants exposed to $260 \mu \mathrm{mol} \mathrm{m} \mathrm{m}^{-2} \mathrm{~s}^{-1}$ for $30 \mathrm{~min}$ prior to 15 -min dark relaxation. Error bars represent scanning electron microscopy (SEM; $n=5)$. A saturating pulse was applied $10 \mathrm{~s}$ after the end of the light exposure to measure $\mathrm{q}_{\mathrm{Pd}}$ and after the 15-min dark period to measure $q_{\mathrm{I}}$ and $F_{\mathrm{v}} / F_{\mathrm{m}}$ 
RCs remain open $>200 \mu \mathrm{mol} \mathrm{m}{ }^{-2} \mathrm{~s}^{-1}$ (data not shown). However, there is still a considerable $q_{1}$ component remaining, which is greater in the WT plants relative to L17. Taken together, these two parameters suggest that photodamage (i.e., $q_{1}$ ) cannot be equated to photoinhibition, as the RCs remain fully open.

\section{4 | DISCUSSION}

Quantifying protective processes within the photosynthetic antenna has been a difficult task, often requiring lengthy disruptive biochemical techniques. However, a novel methodology utilizing the non-invasive photochemical fluorescence quenching coefficient in the dark $\left(q_{\mathrm{Pd}}\right)$ to assess the onset of the photoinactivation of RClls has recently been developed. Because FR light is promptly employed, AL treatments do not need to be interrupted to gauge the functionality of RCII (Ware et al., 2016). This technique allows the actual $\Phi_{\text {PSII }}$ to be measured during a variety of light treatments and also quantifies how pNPQ is. Furthermore, the use of effectors and mutants allows $\mathrm{pNPQ}$ to be disentangled from the operation of the PSII repair cycle, thus enabling us to monitor function of PSII over different timescales.

\subsection{NPQ contributes more to phototolerance than D1 repair during short periods of illumination}

Within this study, a series of inhibitors and mutants of NPQ and the PSII repair cycle were employed in order to calculate the contribution of each process to the phototolerance of $A$. thaliana. The fluorescence procedure (Figure 1) employed here enables the generation of light tolerance curves. Features of these curves can be used to calculate the relative contribution of D1 repair versus $\mathrm{PNPQ}$ to phototolerance (Figure 7). Under WT NPQ conditions (Control), the contribution of pNPQ to tolerance can be calculated as the percentage difference in the light intensity causing $50 \%$ photoinactivation $\left(1_{50 \%}\right.$; i.e., the light intensity where $50 \%$ of the population have a $\mathrm{q}_{\mathrm{Pd}}$ value $<0.98$ ) in chloroplasts or leaves infiltrated with lincomycin relative to WT (Figures $2 b$ and 3a). Lincomycin is known to block D1 repair, and thus, any phototolerance can be approximately be attributed to PNPQ (Belgio, Johnson, Jurić, \& Ruban, 2012; Belgio, Ungerer, \& Ruban, 2015). Alternatively, the percentage difference between the $I_{50 \%}$ value in the presence of an uncoupler $\left(\mathrm{NH}_{4} \mathrm{Cl}\right.$ or nigericin) or in a mutation preventing the PSII repair cycle (var2-2) relative to WT can be approximately attributed to phototolerance resulting from D1 repair. Under WT NPQ conditions, an average of $17 \%$ phototolerance can be attributed to $\mathrm{D} 1$ repair and $83 \%$ to $\mathrm{pNPQ}$ (Figure $7 \mathrm{~B}$ ), during short periods of illumination. This is in agreement with the reduced $\mathrm{q}_{\mathrm{Pd}}$ value at the end of the AL routine in the uncoupler-treated WT or var2-2 plants relative to WT (Figures 2c, 3b, and 5b).

The contribution of D1 repair versus $\mathrm{PNPQ}$ to phototolerance can also be calculated under enhanced NPQ conditions (Figure 7a). For chloroplasts, this can be calculated as the percentage difference between lincomycin-treated and WT chloroplasts in the presence of DAD (Figure 2b). In leaves, this can be calculated as the percentage difference between lincomycin-treated L17 and control infiltrated L17 leaves (Figure 3a). Under enhanced NPQ conditions, the contribution of D1 repair versus $\mathrm{PNPQ}$ becomes even more disparate, where on average only $13.5 \%$ can be attributed to D1 repair (Figure $7 b$ ). This supports the important role of NPQ as a mechanism that lowers the effective light intensity, leading to the lowering of the rate of photoinactivation and photodamage. This shift is corroborated by previous work to study the photoinhibitory damage using NPQ-deficient mutants. Ware et al. (2014) infiltrated leaves of WT Col-0, npq1, and npq4 (zeaxanthin- and PsbS-deficient plants, respectively) with nigericin and used a constant high light $\left(1,500 \mu \mathrm{mol} \mathrm{m}^{-2} \mathrm{~s}^{-1}\right)$ procedure to assess the $q_{1}$ component of NPQ. This $q_{1}$ component was found to be greater and account for a larger fraction of total NPQ, in the mutants relative to WT (fig. 10 in Ware et al., 2014). The results of this current study indicate that damage occurs at even low light intensities, but with much slower rate comparable to the rate of repair. Therefore, if the rate of repair is able to match the rate of photodamage, the PSII repair cycle can provide phototolerance even in the total absence of NPQ. Thus, under these short-term conditions, and where NPQ is inhibited by uncouplers, a certain degree of the light tolerance can be maintained (Figure 7a,b). Hence, in the long run, D1 turnover becomes an important mechanism to ensure light tolerance. Overall, this indicates that the amount of $\mathrm{pNPQ}$ present is the determining factor in phototolerance but that capacity for repair is also important, even under short-term illumination.

The increasing $A L$ procedure represents one possible scenario of light conditions a plant could experience. Increasing AL steps are representative of a sunrise on a cloudless day (Ware et al., 2014) and favour the establishment of NPQ without time pressure. However, this scenario does not consider rapid fluctuations in light, which would be present in many natural environments, nor prolonged periods of high light. Previous work has indicated the importance of the PSII repair cycle during constant, high light illumination. Ruban and Belgio (2014) found that leaves exposed to high light $\left(1,500 \mu \mathrm{mol} \mathrm{m} \mathrm{m}^{-2} \mathrm{~s}^{-1}\right)$ for 40 min show the same kinetics of recovery of $\mathrm{q}_{\mathrm{Pd}}$ as those reported for the repair of degraded D1 protein (timescale of hours; Aro et al., 1993; Andersson \& Aro, 2001; fig. 2B in Ruban \& Belgio, 2014). Ruban and Belgio (2014) also carried out the same experiment on leaves infiltrated with lincomycin and were unable to restore $\mathrm{q}_{\mathrm{Pd}}$ to 1.00 over $6 \mathrm{hr}$ of measurement. The same experimental set-up can also be used to calculate the contribution of D1 repair versus NPQ under a constant, high light procedure. This enables the assessment of each process under conditions where NPQ is not able to establish fully (Ware et al., 2014). Figure 4 shows the results of a similar experiment carried out on WT Col-0 leaves infiltrated with lincomycin and nigericin during $40 \mathrm{~min}$ of $2,100 \mu \mathrm{mol} \mathrm{m} \mathrm{m}^{-2} \mathrm{~s}^{-1}$. The contribution of $\mathrm{pNPQ}$ and D1 repair to photoprotection can be calculated as the relative difference in the time taken for $\mathrm{q}_{\mathrm{Pd}}$ to decline below 0.98 in lincomycin-/nigericintreated plants relative to the control (Figure 7c). This indicates a shift in the balance between the two processes, with D1 able to contribute a greater amount $(\sim 28.5 \%)$ to photoprotection under conditions in which NPQ is unable to form.

Within this study, only short periods of illumination ( 40 min) were considered. Previous work has shown that similar timescales ( $30 \mathrm{~min})$ of constant high light $\left(2,000 \mu \mathrm{mol} \mathrm{m} \mathrm{m}^{-2} \mathrm{~s}^{-1}\right)$ were not sufficient to lead to a significant reduction in D1 protein content, despite a large reduction in $\mathrm{q}_{\mathrm{Pd}}$ (Giovagnetti \& Ruban, 2015). This is due to 
(a)

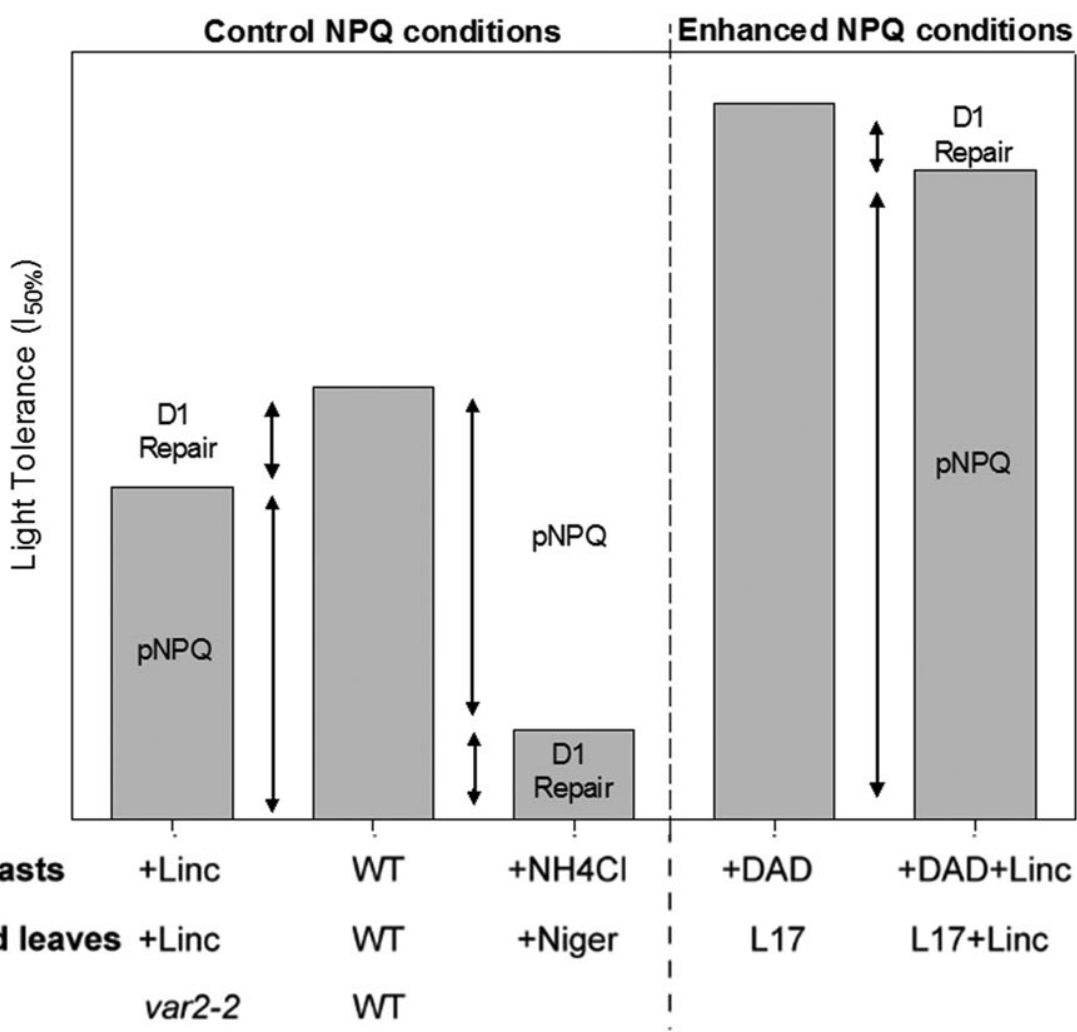

(b)

$\begin{array}{lrll}\text { Chloroplasts } & \text { +Linc } & \text { WT } & +\mathrm{NH} 4 \mathrm{Cl} \\ \text { Infiltrated leaves } & + \text { Linc } & \text { WT } & \text { +Niger } \\ \text { Plants } & \text { var2-2 } & \text { WT } & \end{array}$

Enhanced NPQ conditions

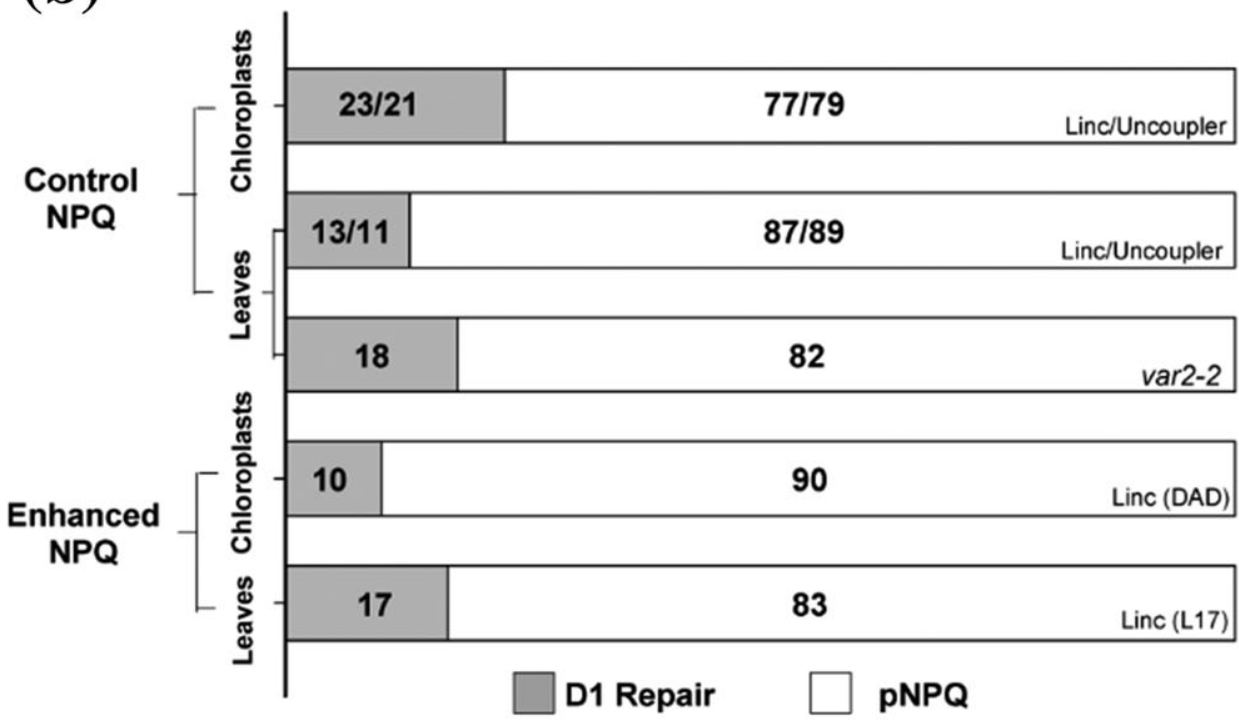

(c)

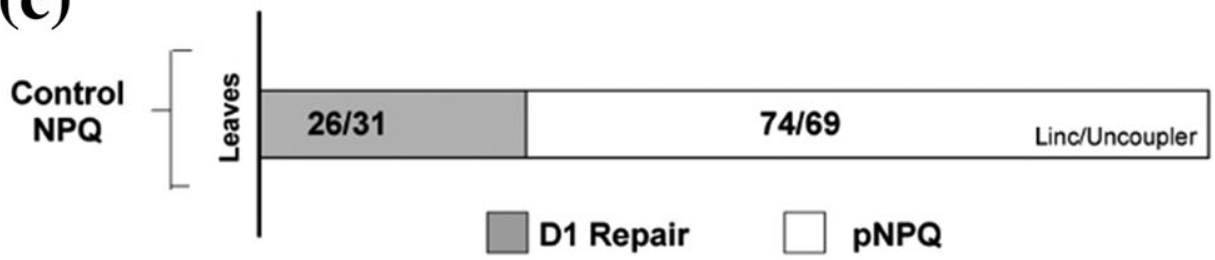

FIGURE 7 (a) The contribution of D1 repair and protective nonphotochemical quenching (pNPQ) can be calculated as the percentage difference in light intensity causing $50 \%$ photoinactivation between treatments and wild type (WT) under control NPQ conditions or between treatment and DAD/L17 leaves under enhanced NPQ conditions. (b) Percentage contribution of pNPQ versus D1 repair to photoprotection in chloroplasts, infiltrated leaves, and whole plants as calculated in (a) using data from Figures 2, 3, and 5. (c) The contribution of D1 repair and pNPQ under constant illumination conditions can be calculated as the percentage difference between the time taken for q $_{\mathrm{Pd}}$ to drop below 0.98 as shown in Figure $4 \mathrm{~b}$ for infiltrated leaves. $\mathrm{DAD}=$ diaminodurene 
the insufficient time available for removal of the damaged polypeptide (Aro et al., 1993; Tyystjärvi, 2013). It can therefore be expected that a longer illumination procedure would again shift the contribution of photoprotection more in favour of D1 repair, as it would allow sufficient time for the PSII repair cycle to be up-regulated. Such measurements are beyond the scope of this study but could, in future, indicate the long-term action of photoprotective processes. The integration of protective processes in the photosynthetic membrane means that altering a single process will also have effects on another. For example, NPQ is involved in protecting the PSII repair machinery from oxidative damage, so any alteration to the NPQ process, either negative or positive (i.e., overexpression), will also effect the PSII repair cycle (Murata et al., 2012; Takahashi et al., 2009; Takahashi \& Badger, 2011). Conversely, use of lincomycin or the var2-2 mutant is also not completely specific to blocking the PSII repair cycle, although they have been used synonymously for this purpose in the past (e.g., Bailey et al., 2002; Tikkanen, Mekala, \& Aro, 2014). Further, the redundancy in protective processes means that knocking out one process will not necessarily negatively impact photoprotection as whole. However, although these treatments are not perfect for completely isolating each mechanism, the combination of treatments does give an approximate correlation to processes protecting the photosynthetic machinery and allow the relative contributions of each to be elucidated under different conditions. Taken together, the results presented in Figure 7b,c, plus previous work on D1 protein degradation and photoinhibitory quenching (e.g., Giovagnetti \& Ruban, 2015; Ware et al., 2014), indicate the dynamic nature of the processes governing photoprotection and photodamage in higher plants. This further indicates the importance of the $\mathrm{q}_{\mathrm{Pd}}$ parameter in reflecting the status of the RCs and its accessibility for the measurement of photodamage and photoprotection under different light conditions or treatments. Indeed, the new system of separation of photodamage from photoprotection should become instrumental in the studies of the combination of stresses, such as light and temperature or light and water stress (Suzuki, Rivero, Shulaev, \& Blumwald, 2014; Yamamoto, 2016). These additional stressors or combination of stressors are likely to affect both the processes of D1 repair and pNPQ, including xanthophyll cycle activity, electron and proton transport, and the photosynthetic membrane protein phosphorylation, amongst others (Yamamoto, 2016). Hence, the study of the contribution of these events to overall light tolerance will be the first step in understanding dynamic control of phototolerance in the context of synergistic interactions of the various stress factors.

\section{2 | Photoinactivation, photodamage, and photoinhibition: The protective nature of sustained NPQ components}

This work highlights the misleading nature of terms associated with damage to photosynthetic machinery and the need to distinguish between photoinactivation, photodamage, and photoinhibition, the latter of which encompasses both photodamage and sustained downregulation via slowly reversible NPQ. The classical experiment presented in Figure 5 shows that despite a large $\mathrm{q}_{\mathrm{I}}$ component, the $\mathrm{q}_{\mathrm{Pd}}$ value of 1.00 in both WT and L17 plants indicates that RCs are fully open and functioning. This suggests that $\mathrm{q}_{\mathrm{Pd}}$ and $\mathrm{pNPQ}$ are more accurate fluorescence parameters for measuring the function of RCs and the extent of photoinactivation, and that previously used parameters, namely, $F_{\mathrm{v}} / F_{\mathrm{m}}$ and $\mathrm{q}_{\mathrm{l}}$, should be treated with caution. When used correctly, $F_{v} / F_{m}$ or $q_{1}$ can give useful information on pre-existing processes affecting PSII efficiency (for more details, see Demmig-Adams et al., 2012); however, they are often ambiguous as to their measurement and can be difficult to interpret (Murchie \& Lawson, 2013). For example, $F_{\mathrm{v}} / F_{\mathrm{m}}$ is often used as an indicator of stress, yet $F_{\mathrm{v}} / F_{\mathrm{m}}$ can vary naturally within and between species or even between seasons within the same individual (e.g., Demmig-Adams et al., 2012; Demmig-Adams, Garab, Adams, \& Govindjee, 2014). Traditionally, q was assumed to result only from damage to PSII (Quick \& Stitt, 1989; Roháček, 2010; Walters \& Horton, 1991). However, evidence is increasing for the long-term protective role of sustained NPQ components (e.g., Adams et al., 2008; Demmig-Adams et al., 2012, 2014). For example, exposure of a deep shade acclimated plant or leaf to high light conditions leads to small initial amounts of NPQ and slow recovery of $F_{\mathrm{v}} / F_{\mathrm{m}}$ following the return to darkness (Adams et al., 2006; Demmig-Adams et al., 2012; Förster, Pogson, \& Osmond, 2011). Although such features are often interpreted as photodamage, they have more recently thought to represent a sustained photoprotective state (Demmig-Adams et al., 2012). Sustained NPQ is also seen in stress tolerant species, growing in unfavourable environments. Longterm retention of zeaxanthin (and antheraxanthin) in evergreen conifers has been postulated to enable season-long, sustained thermal dissipation, thought to provide photoprotection and survival during winter (see Adams et al., 2008, and Demmig-Adams et al., 2012, 2014 and references within). The PSII repair cycle has also been proposed as a mechanism that enables active and tight regulation of photodamage, as opposed to a simple consequence of the need to restore function (Demmig-Adams et al., 2012; Järvi et al., 2015). Although the vulnerability of PSII was originally considered to be a fault in the photosynthetic machinery, it has recently been proposed as a means to limit photodamage to PSII and thus protect PSI that is not thought to have its own repair cycle (Järvi et al., 2015; Sonoike, 2011; Tikkanen et al., 2014). The q component reported in this study may therefore indicate the presence of long-term $\mathrm{pNPQ}$ components.

$F_{\mathrm{v}} / F_{\mathrm{m}}$ and $\mathrm{q}_{\mathrm{l}}$ components are not redundant parameters; they can offer information on the $\Phi_{\mathrm{PSII}}$. They do however fail to instantly discern between the permanently damaged and the temporarily inactivated components like the $\mathrm{q}_{\mathrm{Pd}}$ parameter does. Indeed, there are drawbacks and assumptions to using fluorescence (see Murchie \& Lawson, 2013 for further details), but here, we make a case for the use of $\mathrm{q}_{\mathrm{Pd}}$ and $\mathrm{pNPQ}$ parameters as more reliable and informative fluorescence detection parameters. There are also limitations to the use of Western blots, namely, the delay between photodamage and D1 protein detection, the long treatments times required for a detectable decrease in D1 protein content, and the variability in protein quantification. Similar issues are also present for oxygen electrode measurements, such as the need to isolate chloroplasts and the instruments intricate set-up. The unique benefits of fluorescence measurements is the ability to use them for in vivo and in vitro studies, real-time in situ detection of photosynthetic performance, and the adaptability of devices for laboratory, underwater, and field measurements. Indeed, 
fluorescence analysis has shown here that small changes $( \pm 0.01 \%)$ in RCII inactivation can be detected within a much smaller timeframe and to a greater degree of accuracy than Western blot analysis. Despite previous findings that D1 protein repair takes 1-2 hr, this work demonstrates that photoinactivation can occur within short-term timeframes (<45 min) and that PSII repair contributes to approximately $20 \%$ of $\Phi_{\text {PSII. }}$. This novel result shows that PSII reactivation and repair is vitally important during short-term illumination, despite it being less important than pNPQ for maintaining $\Phi_{\mathrm{PSII}}$. This work hopefully illustrates many of these benefits and encourages the use of $\mathrm{q}_{\mathrm{Pd}}$ and $\mathrm{pNPQ}$ parameters for users conducting fluorescence-based experiments.

Although the capacity and kinetics of NPQ can be highly diverse across lineages, with alternative components known to be present in algae and cyanobacteria, NPQ is essential and common to all photosynthetic organisms and it is likely that many features are conserved (Demmig-Adams et al., 2014; Derks, Schaven, \& Bruce, 2015; Goss \& Lepetit, 2015; Ruban et al., 2012). This means that measurements on a range of photosynthetic organisms could be used as a means to study NPQ and could further highlight the dynamic nature and the diversity in photoprotective mechanisms.

\section{5 | CONCLUSIONS}

Within this study, a PAM fluorescence methodology was used to assess the contribution of NPQ and D1 repair to photoprotection under short periods of illumination ( $40 \mathrm{~min}$ ). New fluorescence parameters $\mathrm{q}_{\mathrm{Pd}}$ and $\mathrm{pNPQ}$ provide a rapid and non-invasive method of assessing RCll functionality. This highlights the dynamic nature of processes governing light harvesting and energy utilization, with the balance between different processes dependent on the prevailing light conditions and the plant's capacity for NPQ. Although this study represents the first step in assessing the balance between processes ensuring light tolerance in higher plants, future studies are required to further assess contribution of pNPQ and D1 repair processes in different photosynthetic organisms and under more realistic (e.g., fluctuating) and longer term light treatments.

\section{ACKNOWLEDGMENTS}

We would like to thank Prof. Peter Nixon for discussions during the primary stages of the manuscript, Dr. Joanna Sacharz for overseeing the SDS-PAGE and Western blots, and Dr. Vasco Giovagnetti and Dr. Petra Ungerer for helpful discussion and critical reading of the manuscript. The authors declare that there is no conflict of interest in this work.

\section{FUNDING}

A. V. R. acknowledges support from the Royal Society Wolfson Research Merit Award and a BBSRC Grant BB/L019027/1. A. J. T. was supported by BBSRC Grant BB/L019027/1. M. A. W. was recipient of the Queen Mary Principals research studentship.

\section{AUTHOR CONTRIBUTIONS}

A. V. R. conceived the idea of the project and supervised the experiments. M. A. W. and A. V. R. developed original screening procedures.
A. J. T. and M. A. W performed the experiments and analysed the data. A. J. T. wrote the first manuscript draft with contributions of all the authors. A. V. R. supervised and complemented the writing.

\section{ORCID}

Alexander V. Ruban (10 http://orcid.org/0000-0001-8554-0249

\section{REFERENCES}

Adams, W. W. III, \& Demmig-Adams, B. (2004). Chlorophyll fluorescence as a tool to monitor plant response to the environment. In G. C. Papageorgiou, \& Govindjee (Eds.), Chlorophyll a fluorescence: A signature of photosynthesis (pp. 583-604). Dordrecht, Netherlands: Springer.

Adams, W. W. III, Demmig-Adams, B., \& Winter, K. (1990). Relative contributions of zeaxanthin-related and zeaxanthin-unrelated types of 'high energy-state' quenching of chlorophyll fluorescence in spinach leaves exposed to various environmental conditions. Plant Physiology, 92, 302-309.

Adams, W. W. III, Zarter, C. R., Mueh, K. E., Amiard, V., \& Demmig-Adams, B. (2006). Energy dissipation and photoinhibition: A continuum of photoprotection. In B. Demmig-Adams, W. W. Adams, \& A. K. Mattoo (Eds.), Photoprotection, photoinhibition, gene regulation, and environment (pp. 49-64). Dordrecht, The Netherlands: Springer.

Andersson, B., \& Aro, E.-M. (2001). Photodamage and D1 protein turnover in photosystem II. In E.-M. Aro, \& B. Andersson (Eds.), Regulation of photosynthesis (pp. 377-393). Dordrecht, The Netherlands: Kluwer Academic.

Aro, E.-M., Virgin, I., \& Andersson, B. (1993). Photoinhibition of photosystem II-Inactivation, protein damage and turnover. Biochimica et Biophysica Acta, 1143, 113-134.

Bailey, S., Thompson, E., Nixon, P. J., Horton, P., Mullineaux, C. W., Robinson, C., \& Mann, N. H. (2002). A critical role for the Var2 FtsH homologue of Arabidopsis thaliana in the photosystem II repair cycle in vivo. Journal of Biological Chemistry, 277(3), 2006-2011.

Barber, J. (1995). Molecular basis of the vulnerability of photosystem II to damage by light. Australian Journal of Plant Physiology, 22, 201-208.

Belgio, E., Johnson, M. P., Jurić, S., \& Ruban, A. V. (2012). Higher plant photosystem II light harvesting antenna, not the reaction center, determines the excited state lifetime-Both the maximum and the nonphotochemically quenched. Biophysical Journal, 102, 2761-2771.

Belgio, E., Ungerer, P., \& Ruban, A. V. (2015). Light-harvesting superstructures of green plant chloroplasts lacking photosystems. Plant, Cell \& Environment, 38(10), 2035-2047.

Boekema, E. J., van Roon, H., \& Dekker, J. P. (1998). Specific association of photosystem II and light-harvesting complex II in partially solubilized photosystem II membranes. FEBS Letters, 424, 95-99.

Brooks, M. D., \& Niyogi, K. K. (2011). Use of a pulse-amplitude modulated chlorophyll fluorometer to study the efficiency of photosynthesis in Arabidopsis plants. Methods in Molecular Biology, 775, 299-310.

Butler, W. L. (1978). Energy distribution in the photochemical apparatus of photosynthesis. Annual Review of Plant Physiology, 29, 457-478.

Canovas, P. M., \& Barber, J. (1993). Detection of a 10 kDa breakdown product containing the $\mathrm{C}$-terminus of the D1-protein in photoinhibited wheat leaves suggests an acceptor side mechanism. FEBS Letters, 324, 341-344.

Carvalho, F. E., Ware, M. A., \& Ruban, A. V. (2015). Quantifying the dynamics of light tolerance in Arabidopsis plants during ontogenesis. Plant, Cell \& Environment, 38(12), 2603-2617.

Crouchman, S., Ruban, A. V., \& Horton, P. (2006). PsbS enhances nonphotochemical fluorescence quenching in the absence of zeaxanthin. FEBS Letters, 580(8), 2053-2058.

Danielsson, R., Suorsa, M., Paakkarinen, V., Albertsson, P. Å., Styring, S., Aro, E. M., \& Mamedov, F. (2006). Dimeric and monomeric organization of photosystem II distribution of five distinct complexes in the different domains of the thylakoid membrane. Journal of Biological Chemistry, 281(20), 14241-14249. 
Demmig, B., \& Björkman, O. (1987). Comparison of the effect of excessive light on chlorophyll fluorescence $(77 \mathrm{~K})$ and photon yield of $\mathrm{O}_{2}$ evolution in leaves of higher plants. Planta, 171(2), 171-184.

Demmig, B., \& Winter, K. (1988). Characterisation of three components of non-photochemical fluorescence quenching and their response to photoinhibition. Australian Journal of Plant Physiology, 15, 163-177.

Demmig, B., Winter, K., Kruger, A., \& Czygan, F. C. (1987). Photoinhibition and zeaxanthin formation in intact leaves: A possible role of the xanthophyll cycle in the dissipation of excess light. Plant Physiology, 84, 218-224.

Demmig-Adams, B., \& Adams, W. W. III (2006). Photoprotection in an ecological context: The remarkable complexity of thermal energy dissipation. New Phytologist, 172, 11-21.

Demmig-Adams, B., Cohu, C. M., Muller, O., \& Adams, W. W. III (2012) Modulation of photosynthetic energy conversion efficiency in nature: From seconds to seasons. Photosynthesis Research, 113(1-3), 75-88.

Demmig-Adams, B., Garab, G., Adams, W. W. III, \& Govindjee (2014). Nonphotochemical quenching and energy dissipation in plants, algae and cyanobacteria. New York, USA: Springer.

Derks, A., Schaven, K., \& Bruce, D. (2015). Diverse mechanisms for photoprotection in photosynthesis. Dynamic regulation of photosystem II excitation in response to rapid environmental change. Biochimica et Biophysica Acta (BBA)-Bioenergetics, 1847(4), 468-485.

Fiekers, J. F., Marshal, I. B., \& Parsons, R. L. (1979). Clindamycin and lincomycin alter miniature endplate current decay. Nature, 281, 680-682.

Förster, B., Pogson, B. J., \& Osmond, C. B. (2011). Lutein from deepoxidation of lutein epoxide replaces zeaxanthin to sustain an enhanced capacity for nonphotochemical quenching in avocado leaves in the dark. Plant Physiology, 156, 393-403.

Funk, C., Schroder, W. P., Napiwotzki, A., Tjus, S. E., Renger, G., \& Andersson, B. (1995). The PSII-S protein of higher-plants-A new type of pigment-binding protein. Biochemistry, 34, 11133-11141.

Genty, B., Briantais, J.-M., \& Baker, N. R. (1989). The relationship between the quantum yield of photosynthetic electron-transport and quenching of chlorophyll fluorescence. Biochimica et Biophysica Acta, 990, 87-92.

Genty, B., Goulas, Y., Dimon, B., Peltier, G., Briantais, J. M., \& Moya, I. (1992). Modulation of efficiency of primary conversion in leaves, mechanisms involved at PS2. In N. Murata (Ed.), Research in photosynthesis, Vol. IV: Proceedings of IXth International Congress on Photosynthesis (pp. 603-610). Nagoya, Japan: Kluwer Academic Publishers. August 30September 4.

Giovagnetti, V., \& Ruban, A. V. (2015). Discerning the effects of photoinhibition and photoprotection on the rate of oxygen evolution in Arabidopsis leaves. Journal of Photochemistry and Photobiology B: Biology, 152, 272-278.

Goral, T. K., Johnson, M. P., Duffy, C. D., Brain, A. P., Ruban, A. V., \& Mullineaux, C. W. (2012). Light-harvesting antenna composition controls the macrostructure and dynamics of thylakoid membranes in Arabidopsis. Plant Journal, 69, 289-301.

Goss, R., \& Lepetit, B. (2015). Biodiversity of NPQ. Journal of Plant Physiology, 172, 13-32.

Greenberg, B. M., Gaba, V., Mattoo, A. K., \& Edelman, M. (1987). Identification of a primary in vivo degradation product of the rapidly turning-over $32 \mathrm{kD}$ protein of photosystem II. The EMBO Journal, 6, 2865-2869.

Horton, P., \& Hague, A. (1988). Studies on the induction of chlorophyll fluorescence in isolated barley protoplasts: IV. Resolution of nonphotochemical quenching. Biochimica et Biophysica Acta, 932, 107-115.

Horton, P., \& Ruban, A. V. (1992). Regulation of photosystem II. Photosynthesis Research, 34, 375-385.

Horton, P., Wentworth, M., \& Ruban, A. V. (2005). Control of the light harvesting function of chloroplast membranes: The LHCll-aggregation model for non-photochemical quenching. FEBS Letters, 579, 4201-4206.

Jahns, P., \& Holzwarth, A. R. (2012). The role of the xanthophyll cycle and of lutein in photoprotection of photosystem II. Biochimica et Biophysica Acta, 1817, 182-193.
Järvi, S., Suorsa, M., \& Aro, E. M. (2015). Photosystem II repair in plant chloroplasts-Regulation, assisting proteins and shared components with photosystem II biogenesis. Biochimica et Biophysica Acta (BBA)-Bioenergetics, 1847(9), 900-909.

Johnson, M. P., Goral, T. K., Duffy, C. D. P., Brain, A. P. R., Mullineaux, C. W., $\&$ Ruban, A. V. (2011). Photoprotective energy dissipation involves the reorganization of photosystem II light harvesting complexes in the grana membranes of spinach chloroplasts. Plant Cell, 23, 1468-1479.

Johnson, M. P., \& Ruban, A. V. (2011). Restoration of rapidly-reversible photoprotective energy dissipation in the absence of PsbS protein by enhanced $\Delta \mathrm{pH}$. Journal of Biological Chemistry, 286, 19973-19981.

Johnson, M. P., \& Ruban, A. V. (2014). Rethinking the existence of a steadystate $\Delta \psi$ component of the proton motive force across plant thylakoid membranes. Photosynthesis Research, 119(1-2), 233-242.

Kasahara, M., Kagawa, T., Oikawa, K., Suetsugu, N., Miyao, M., \& Wada, M. (2002). Chloroplast avoidance movement reduces photodamage in plants. Nature, 420(6917), 829-832.

Koivuniemi, A., Aro, E.-M., \& Andersson, B. (1995). Degradation of the D1 and D2 proteins of photosystem II in higher plants is regulated by reversible phosphorylation. Biochemistry, 34, 16022-16029.

Krause, G. H. (1974). Changes in chlorophyll fluorescence in relation to light-dependent cation transfer across thylakoid membranes. Biochimica et Biophysica Acta, 333, 301-313.

Krause, G. H. (1988). Photoinhibition of photosynthesis. An evaluation of damaging and protective mechanisms. Physiologia Plantarum, 74, 566-574

Krogmann, D. W., Jagendorf, A. T., \& Avron, A. (1959). Uncouplers of spinach chloroplast photosynthetic phosphorylation. Plant Physiology, 34, 272-277.

Laemmli, U. K. (1970). Cleavage of structural proteins during the assembly of the head of bacteriophage T4. Nature, 227(5259), 680-685.

Latterich, M., \& Patel, S. (1998). The AAA team: Related ATPases with diverse functions. Trends in Cell Biology, 8(2), 65-71.

Li, X.-P., Björkman, O., Shih, C., Grossman, A. R., Rosenquist, M., Jansson, S., \& Niyogi, K. K. (2000). A pigment-binding protein essential for regulation of photosynthetic light harvesting. Nature, 403, 391-395.

Li, X.-P., Phippard, A., Pasari, J., \& Niyogi, K. K. (2002). Structure-function analysis of photosystem II subunit S (PsbS) in vivo. Functional Plant Biology, 29, 1131-1139.

Lindahl, M., Spetea, C., Hundal, T., Oppenheim, A. B., Adam, Z., \& Andersson, B. (2000). The thylakoid FtsH protease plays a role in the light-induced turnover of the photosystem II D1 protein. The Plant Cell, 12(3), 419-431.

Long, S. P., Humphries, S., \& Falkowski, P. G. (1994). Photoinhibition of photosynthesis in nature. Annual Review of Plant Physiology and Plant Molecular Biology, 45, 633-662.

Matsubara, S., \& Chow, W. S. (2004). Populations of photoinhibited photosystem II reaction centers characterized by chlorophyll a fluorescence lifetime in vivo. PNAS, 101, 18234-18239.

Mattoo, A. K., Hoffman-Falk, H., Marder, J. B., \& Edelman, M. (1984). Regulation of protein metabolism: Coupling of photosynthetic electron transport to in vivo degradation of the rapidly metabolized 32kilodalton protein of the chloroplast membranes. PNAS, 81(5), 1380-1384.

Maxwell, K., \& Johnson, G. N. (2000). Chlorophyll fluorescence-A practical guide. Journal of Experimental Botany, 51(345), 659-668.

Murata, N., Allakhverdiev, S. I., \& Nishiyama, Y. (2012). The mechanism of photoinhibition in vivo: Re-evaluation of the roles of catalase, $a-$ tocopherol, non-photochemical quenching, and electron transport. Biochimica et Biophysica Acta (BBA)-Bioenergetics., 1817(8), 1127-1233.

Murchie, E. H., \& Lawson, T. (2013). Chlorophyll fluorescence analysis: A guide to good practice and understanding some new applications. Journal of Experimental Botany, ert208. 
Nanba, O., \& Satoh, K. (1987). Isolation of a photosystem II reaction center consisting of D1 and D2 polypeptides and cytochrome b-559. PNAS, 84, 109-112.

Nilkens, M., Kress, E., Lambrev, P., Miloslavina, Y., Müller, M., Holzwarth, A. R., \& Jahns, P. (2010). Identification of a slowly inducible zeaxanthindependent component of non-photochemical quenching of chlorophyll fluorescence generated under steady-state conditions in Arabidopsis. Biochimica et Biophysica Acta (BBA)-Bioenergetics, 1797(4), 466-475.

Nixon, P. J., Barker, M., Boehm, M., de Vries, R., \& Komenda, J. (2005). $\mathrm{FtsH}$-mediated repair of the photosystem II complex in response to light stress. Journal of Experimental Botany, 56(411), 357-363.

Nixon, P. J., Michoux, F., Yu, J., Boehm, M., \& Komenda, J. (2010). Recent advances in understanding the assembly and repair of photosystem II. Annals of Botany, 106, 1-16.

Noctor, G., Rees, D., Young, A., \& Horton, P. (1991). The relationship between zeaxanthin, energy-dependent quenching of chlorophyll fluorescence and the transthylakoid $\mathrm{pH}$-gradient in isolated chloroplasts. Biochimica et Biophysica Acta, 1057, 320-330.

Ohad, I., Kyle, D. J., \& Arntzen, C. J. (1984). Membrane-protein damage and repair-Removal and replacement of inactivated 32-kilodalton polypeptides in chloroplast membranes. Journal of Cell Biology, 99, 481-485.

Oxborough, K., \& Baker, N. R. (1997). Resolving chlorophyll a fluorescence of photosynthetic efficiency into photochemical components-Calculation of $\mathrm{qP}$ and $\mathrm{Fv}^{\prime} / \mathrm{Fm}^{\prime}$ without measuring Fo. Photosynthesis Research, 54, 135-142.

Porra, R. J., Thompson, W. A., \& Kriedemann, P. E. (1989). Determination of accurate extinction coefficients and simultaneous-equations for assaying chlorophyll a and chlorophyll b extracted with 4 different solvents-verification of the concentration of chlorophyllstandards by atomic-absorption spectroscopy. BiochimBiophys Acta, 975, 384-394.

Powles, S. B. (1984). Photoinhibition of photosynthesis induced by visible light. Annual Review of Plant Physiology, 35, 15-44.

Prior, C., Fiekers, J. F., Henderson, F., Dempster, J., Marshall, I. G., \& Parsons, R. L. (1990). End-plate ion channel block produced by lincosamide antibiotics and their chemical analogs. Journal of Pharmacology and Experimental Therapeutics, 55, 1170-1176.

Quick, W. P., \& Stitt, M. (1989). An examination of factors contributing to non-photochemical quenching of chlorophyll fluorescence in barley leaves. Biochimica et Biophysica Acta (BBA)-Bioenergetics, 977(3), 287-296.

Rees, D., Noctor, G. D., \& Horton, P. (1990). The effect of high-energy-state excitation quenching on maximum and dark level chlorophyll fluorescence yield. Photosynthesis Research, 25(3), 199-211.

Rees, D., Noctor, G. D., Ruban, A. V., Crofts, J., Young, A., \& Horton, P. (1992). pH dependent chlorophyll fluorescence quenching in spinach thylakoids from light treated or dark adapted leaves. Photosynthesis Research, 31, 11-19.

Rees, D., Young, A., Noctor, G., Britton, G., \& Horton, P. (1989). Enhancement of the $\Delta \mathrm{pH}$-dependent dissipation of excitation energy in spinach chloroplasts by light-activation; correlation with the synthesis of zeaxanthin. FEBS Letters, 256, 85-90.

Roháček, K. (2010). Method for resolution and quantification of components of the non-photochemical quenching (qN). Photosynthesis Research, 105(2), 101-113.

Ruban, A. V. (2009). Plants in light. Communicative \& Integrative Biology, 2 , 50-55.

Ruban, A. V. (2012). The photosynthetic membrane: molecular mechanisms and biophysics of light harvesting. Oxford: Wiley-Blackwell.

Ruban, A. V. (2016). Non-photochemical chlorophyll fluorescence quenching: Mechanism and effectiveness in protection against photodamage. Plant Physiology, 170, 1903-1916.

Ruban, A. V., \& Belgio, E. (2014). The relationship between maximum tolerated light intensity and non-photochemical chlorophyll fluorescence quenching: Chloroplast gains and losses. Philosophical Transactions of the Royal Society of London B, 369, 20130222.
Ruban, A. V., \& Horton, P. (1999). The xanthophyll cycle modulates the kinetics of nonphotochemical energy dissipation in isolated light harvesting complexes, intact chloroplasts and leaves. Plant Physiology, 119, 531-542.

Ruban, A. V., Johnson, M. P., \& Duffy, C. D. P. (2012). Photoprotective molecular switch in photosystem II. Biochimica et Biophysica Acta, 1817, 167-181.

Ruban, A. V., \& Murchie, E. H. (2012). Assessing the photoprotective effectiveness of non-photochemical chlorophyll fluorescence quenching: A new approach. Biochimica et Biophysica Acta, 1817, 977-982.

Ruban, A. V., Solovieva, S., Lee, P. J., Ilioaia, C., Wentworth, M., Ganeteg, U., ... Horton, P. (2006). Plasticity in the composition of the light harvesting antenna of higher plants preserves structural integrity and biological function. Journal of Biological Chemistry, 281, 14981-14990.

Ruban, A. V., Young, A. J., \& Horton, P. (1993). Induction of nonphotochemical energy dissipation and absorbance changes in leaves. Evidence for changes in the state of the light-harvesting system of photosystem II in vivo. Plant Physiology, 102, 741-750.

Sacharz, J., Giovagnetti, V., Ungerer, P., Mastroianni, G., \& Ruban, A. V. (2017). The xanthophyll cycle affects reversible interactions between PsbS and light-harvesting complex II to control non-photochemical quenching. Nature Plants, 3(2), 2016225.

Sonoike, K. (2011). Photoinhibition of photosystem I. Physiologia Plantarum, 142(1), 56-64.

Suzuki, N., Rivero, R. M., Shulaev, V., \& Blumwald, E. (2014). Abiotic and biotic stress combinations. New Phytologist, 203, 32-43.

Takahashi, S., \& Badger, M. R. (2011). Photoprotection in plants: A new light on photosystem II damage. Trends in Plant Science, 16(1), 53-60.

Takahashi, S., Milward, S. E., Fan, D. Y., Chow, W. S., \& Badger, M. R. (2009). How does cyclic electron flow alleviate photoinhibition in Arabidopsis? Plant Physiology, 149(3), 1560-1567.

Telfer, A., Bishop, S. M., Phillips, D., \& Barber, J. (1994). Isolated photosynthetic reaction center of photosystem II as a sensitizer for the formation of singlet oxygen. Detection and quantum yield determination using a chemical trapping technique. Journal of Biological Chemistry, 269, 13244-13253.

Theis, J., \& Schroda, M. (2016). Revisiting the photosystem II repair cycle. Plant Signaling \& Behavior, 11(9), e1218587.

Tian, Y., Ungerer, P., Zhang, H., \& Ruban, A. V. (2017). Direct impact of the sustained decline in the photosystem II efficiency upon plant productivity at different developmental stages. Journal of Plant Physiology, 212, 45-53.

Tikkanen, M., Mekala, N. R., \& Aro, E. M. (2014). Photosystem II photoinhibition-repair cycle protects photosystem I from irreversible damage. Biochimica et Biophysica Acta (BBA)-Bioenergetics, 1837(1), 210-205.

Tyystjärvi, E. (2013). Photoinhibition of photosystem II. In International review of cell and molecular biology (Vol. 300) (pp. 243-303). Cambridge, Massachusetts: Academic Press.

Tyystjärvi, E., \& Aro, E.-M. (1996). The rate constant of photoinhibition, measured in lincomycin-treated leaves, is directly proportional to light intensity. PNAS, 93, 2213-2218.

Vass, I., Styring, S., Hundal, T., Koivuniemi, A., \& Aro, E.-M. (1992). Reversible and irreversible intermediates during photoinhibition of photosystem II: Stable reduced QA species promote chlorophyll triplet formation. PNAS, 89, 1408-1412.

Wahadoszamen, M., Berera, R., Ara, A. M., Romero, E., \& van Grondelle, R. (2012). Identification of two emitting sites in the dissipative state of the major light harvesting antenna. Physical Chemistry Chemical Physics, 14, 759-766.

Walters, R. G., \& Horton, P. (1991). Resolution of components of non-photochemical chlorophyll fluorescence quenching in barley leaves. Photosynthesis Research, 27(2), 121-133.

Ware, M. A., Belgio, E., \& Ruban, A. V. (2014). Comparison of the protective effectiveness of NPQ in Arabidopsis plants deficient in 
PsbS protein and zeaxanthin. Journal of Experimental Botany, 66(5), 1259-1270.

Ware, M. A., Belgio, E., \& Ruban, A. V. (2015). Photoprotective capacity of non-photochemical quenching in plants acclimated to different light intensities. Photosynthesis Research, 126(2-3), 261-274.

Ware, M. A., Dall'Osto, L., \& Ruban, A. V. (2016). An in vivo quantitative comparison of photoprotection in Arabidopsis xanthophyll mutants. Frontiers in Plant Science, 7, 841.

Ware, M. A., Giovagnetti, V., Belgio, E., \& Ruban, A. V. (2015). PsbS protein modulates non-photochemical chlorophyll fluorescence quenching in membranes depleted of photosystems. Journal of Photochemistry and Photobiology B: Biology, 152, 301-307.

Yamamoto, Y. (2016). Quality control of photosystem II: The mechanisms for avoidance and tolerance of light and heat stresses are closely linked to membrane fluidity of the thylakoids. Frontiers in Plant Science, 7, 1136.

\section{SUPPORTING INFORMATION}

Additional Supporting Information may be found online in the supporting information tab for this article.

How to cite this article: Townsend AJ, Ware MA, Ruban AV. Dynamic interplay between photodamage and photoprotection in photosystem II. Plant Cell Environ. 2017;1-15. https://doi. org/10.1111/pce.13107 